\title{
ترجمة معاني القرآن بين التشدد العنصري والمغالطات المغرضة
}

\section{Translation of the meaning of the Qoran between racial segregation and fallacious inaccuracies}

\author{
إعداد الباحث/ اجديرة يَس \\ طالب باحث في سلك الدكتور اه، كلية الآداب و العلوم الإنسانية، جامعة محمد الخامس، الرباط، المملكة المغربية
}

E-mail : gyassine@ hotmail.com

Tel. 0032493165659

ملخص:

لقد دخلت الإنسانية بحمد الله في الإسلام بالملايين منذ أن بزغت شمسه في جزيرة العرب وتنزلت كلمات الله عز وجل على رسوله الكريم عليه الصلاة و السلام برسالة سمحة، فياضة بكل المكارم و الخيرات على كل الأفو ام و الثعوب في كل أرجاء الأرض مهما اختلفت أشكالهم و ألو انهم وحضار اتهم وثقافاتهم وكذلك لغاتهم.

لقد أظهرت كل الدر اسـات الحديثة المبنية على أدق التقنيات العلمية أن كل بني البشر سواسية، فلا فضل و لا فروق بينهم

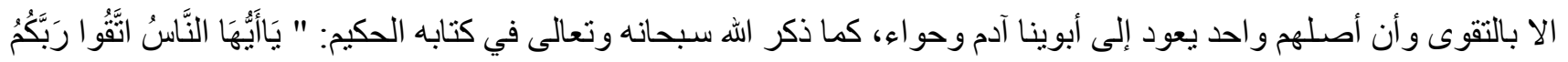

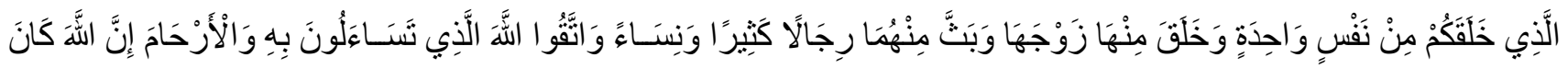

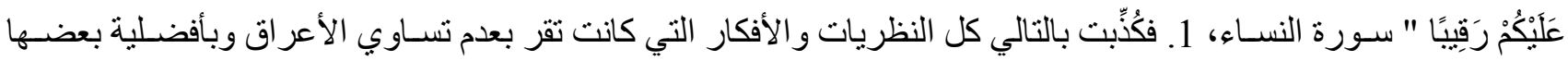



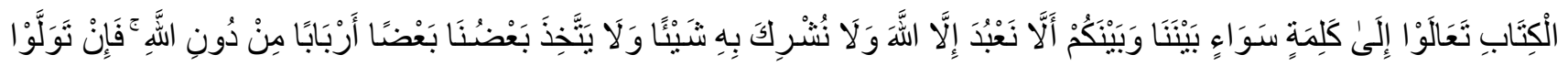

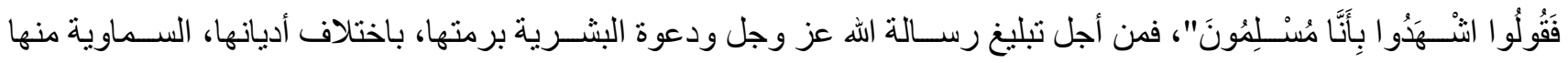
و غير ها، الى هدى الله جل و علا، اتفق علماء الإســلام على جواز نرجمة معاني القرآن، بل وبوجوبها حتى تعم منافعه على كل ذوي البصـــائر النَِّّرة ويحق القول على ذوي القلوب العميـاء، وكذللك من أجل حمايـة كتاب الله تبـارك وتعـالى من الترجمـات اليُغرضـــة لأعداء الدين الحنيف الذين بتربصـــون بنا الدو ائر. لهذا أصــبحنا ملزمين بالتدقيق في ترجماتتا وبتوحيد جهودنا في ترجمة معاني القرآن الكريم.

الكلمات المفتاحية: ترجمة، معاني القرآن، العنصرية، التمييز اللغوي، الاستشراق. 


\title{
Translation of the meaning of the Qoran between racial segregation and fallacious inaccuracies
}

\begin{abstract}
Humanity has entered Islam in millions since its sun began on the island of Arabia. Allah's words have come down on his Holy Messenger with a message of indulgence. All recent studies have shown that all human beings are equal.

There are no differences between them and that they have one origin in Adam and Eve's parents, as Allah stated in his wise book:" O humanity! Be mindful of your Lord Who created you from a single soul, and from it He created its mate, 1 and through both He spread countless men and women. And be mindful of Allah — in Whose Name you appeal to one another — and 'honour' family ties. Surely Allah is ever Watchful over you'. Women (An-Nissa')1. So all the theories and ideas that recognized the inequality of races and the preference for each other fell, and the truth came from Allah and his messenger. "Say, 'O Prophet," "O People of the Book! Let us come to common terms: that we will worship none but Allah, associate none with Him, nor take one another as lords instead of Allah." But if they turn away, then say, "Bear witness that we have submitted 'to Allah alone?." " Family of Imran (Ali ' Imran) 64. In order to convey God's message and to call upon all mankind, in all its religions, divine and other religions, to the right path, Islamic scholars have agreed that the meaning of the Koran may and must be translated for the benefits of the Koran. That is why we are obliged to scrutinize our translations and to unite our efforts in translating the meaning of the Holy Koran.
\end{abstract}

Keywords: Translation, meaning of the Koran, racism, linguistic discrimination, orientalism 


\section{_مقدمة:}

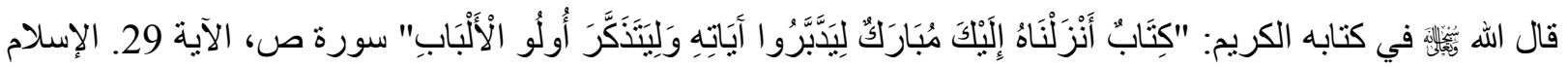
انتشر بمشيئة الله بانتشار رسالته السمحة في كل ربوع العالم حيث يختلف الناس عن أهل جزيرة العرب، مكان نزول الرسالة الإلهية على محمد ابن عبد الله

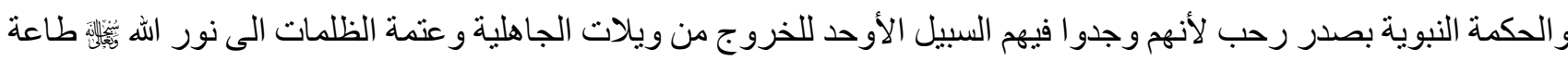

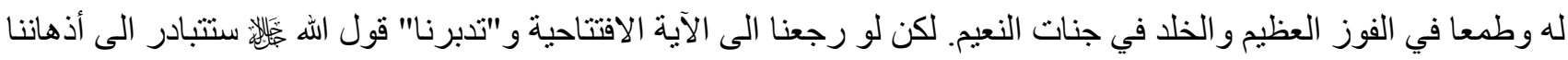
وبطريقة تلقائية أسئلة قد تحير البعض، ولكن بالتدبر والتفكر سنجيب عليها بإذن الله بَّلّ: كيف دخلت الإنسانية في الإسلام

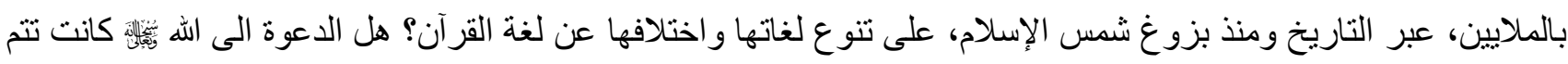

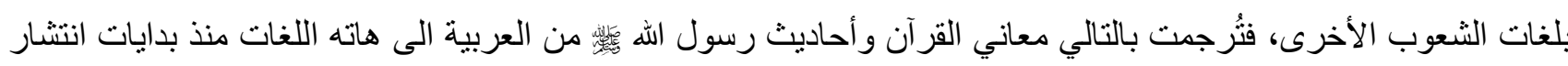

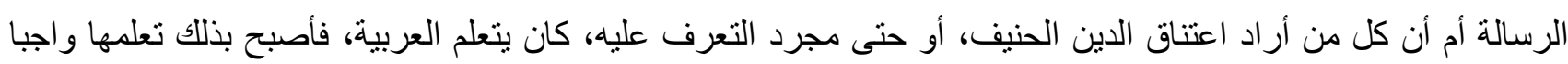

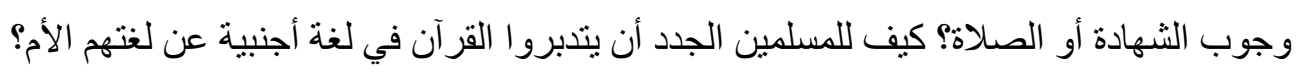
العقل الإنساني هو عبارة عن و عاء يحتوي على عدة معلومات وتفسيرات وتصنيفات للأشياء المحيطة بنا، يستخدم عدة

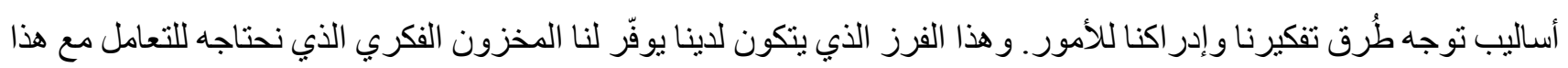
الوسط الذي نعيش فيه، ويمكننا من تحليل كل المعلومات التي تستقبلها أدمغتنا عبر كل فترات حياتتا. فنحن بالتأكيد نرى الآخر من خلال إطار مر هون بتجاربنا الملموسة بالإضافة للمعلومات التي نستقبها عنه وتتم مقاسمتها من طرف الأفراد المكونين للمجتمع الذي ننتمي إليه أو الغرباء عنه، أو من خلال ما نقر أه ونسمعه أو ما نتعلمه في المدارس و الجامعات، وكل هذا يعطبنا نظريات مختلفة عن الوسط المحيط بنا وما يحتوي عليه. وتبدأ الأفكار التي تتكون لاينا في سلك مسار سيء حين نبدأ في التعامل مع الآخر أو المجتمع الآخر بثقافته ولغته وموروثه الحضاري بصورة سلبية، حسب الكيفية التي تريد بها عقولنا بطبيعتها تقسيم عالمنا الى تفر عات ثنائية، وهذه الثنائيات تتمثل جليا في لغتنا: "أنا" و "الآخر " أو "أنا" ضد "الآخر ". إذن فباستطاعتنا الجزم بأن

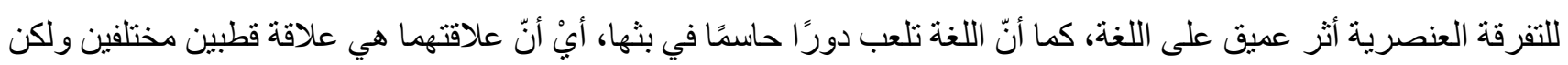
تجمعهما مساحة من التشارك. وهذا بعني أنّ دراسة التمبيز والتفرقة والأفكار المسبقة لا تكتمل إلا بالنظر في اللغة ودورها

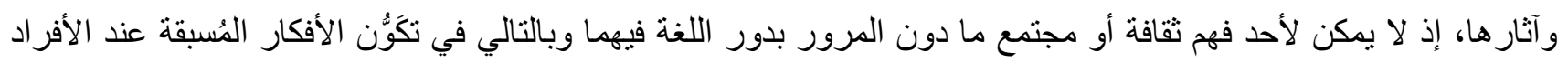
والجماعات. لأن اللغة، فضلا عن كونها طرفا في الهوية الثخصية، سواء الفردية أو الجماعية، فهي ليست فقط وسيلة لنقل الأفكار الإنسانية فحسب، بل هي أيضًا جزء لا يتجز أ من نظام المعلومات الذي يجعل المعطيات تتكون لدينا.

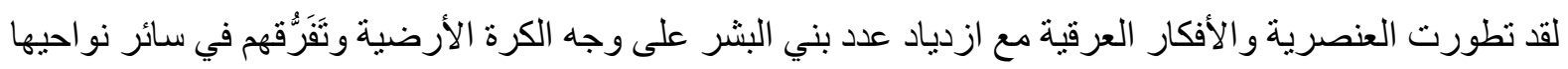
وتحول حالاتهم الفيزيولوجية في اللون و الثنكل وخصوصا في اختلافهم في كل ما يتعلق بالثقافات و اللغات والآثار الحضارية. و العنصرية، كفكرة فقط، هي نابعة من العقل البشري، إذن فلمو اجهتها وجب على الإنسانية إيجاد الحل لكل أنواع التمييز و التفرقة بين أعضائها في المعالجة النفسية لتلك الأو هام الناتجة عن مجمو عة من النظريات الواهية، التي تكونت عبر ناريخ بني الني

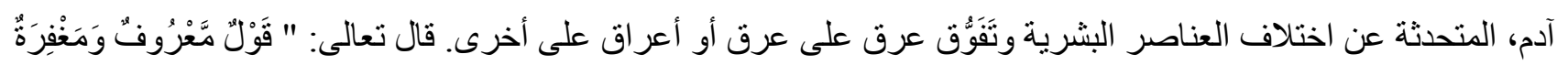

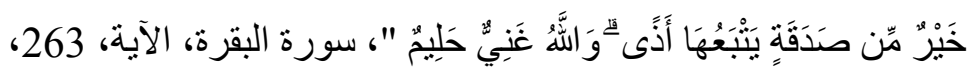




\section{المجلة الدولية لنشر البحوث}

International Journal of Research and Studies Publishing
المجلد الثاني - الإصدار التاسع عشر

تأريخ الإصدار: 20 مايو 2021م

ISSN: 2709-7064

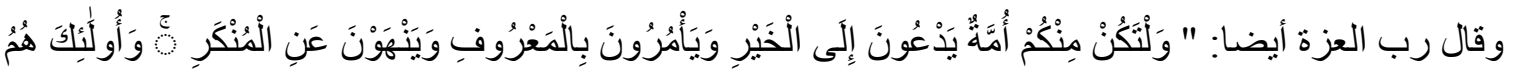


و احد: ضد النكر ، و هو كل ما تعرفه النفس من الخير وتبسأ به وتطمئن إليه" (ابن منظور، 1997). فالعنصرية ناتجة بالأساس عن الخوف من الغريب النكر، ذلك الثخص الذب نجهله فلا تطمئن إليه قلوبنا، فتنكون بذللك لدى الإنسان ردة فعل سلبية اتجاه

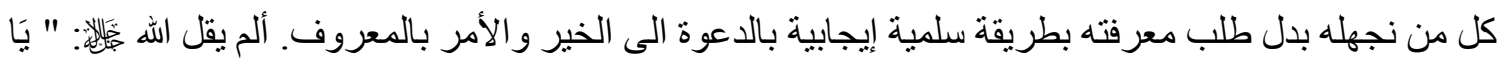

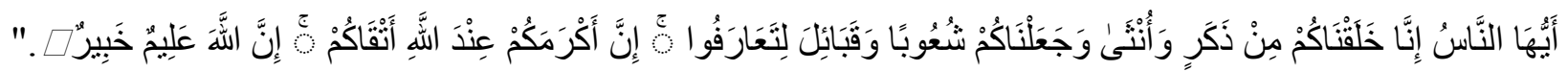
سورة الحجر ات، الآية 13. لهذا فالعنصرية ليست محصورة على العرق أو اللون أو الدين، بل هي تتجلى في التحبز الثقافي و اللغوي أيضا من خلال كل تعبير اتهما وفي مختلف مجالاتهما. حيث، بما أن اللغة هي محور هذه الدراسة، بمكننا القول أنّها تلعب دورًا حاسمًا في التعامل العنصري بالتأثنر على جميع أنتكال العلاقات السلمية بين بني الإنسان.



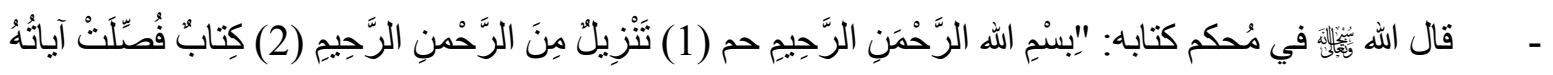



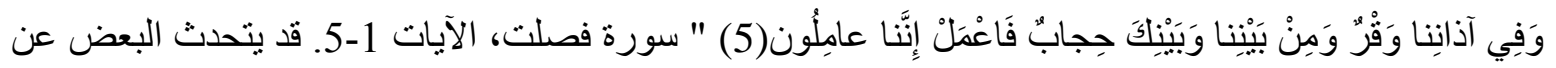
عربية القرآن فيضعها موضع الخطاب الإلهي جاعلا منها لغة مقدسة غير قابلة للترجمة الى لغات العالم حيث لا

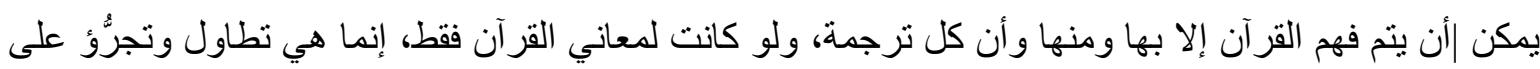

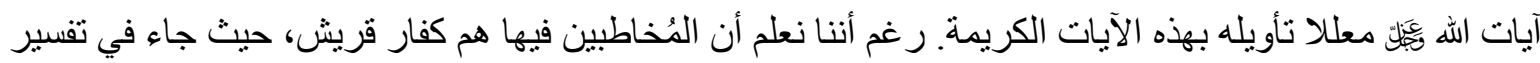

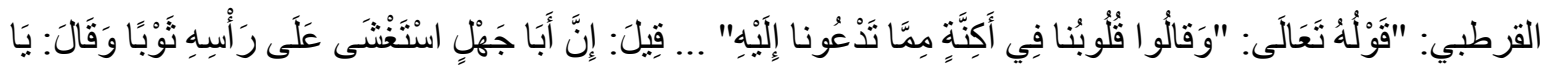

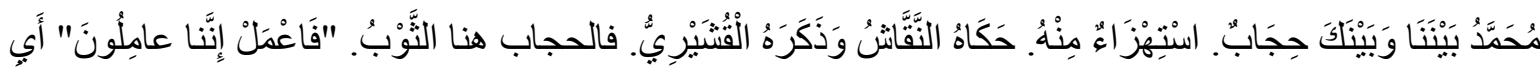

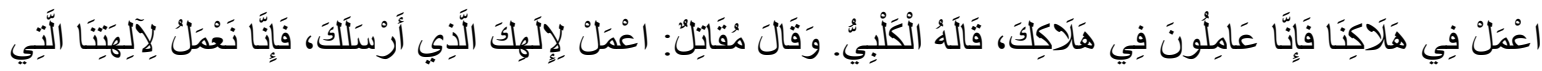

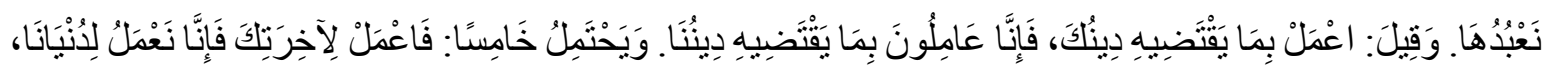

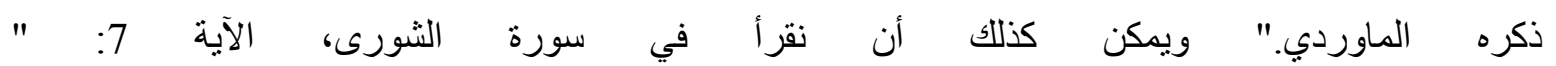

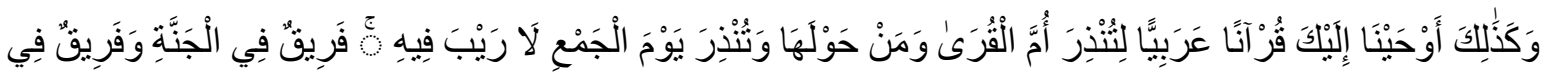
السَّعِيرِ" أي أن القرآن لم يُنَزَّل فقط من أجل العرب الذين يحسنون العربية، بل الى كل من هم حول أم القرى من أعاجم في كل أنحاء الأرض. و هنا تكمن أهمية هذه الدر اسة، حيث سنحاول الإجابة على كل التساؤلات التي بإمكانها أن تبرهن على أن القرآن عربي اللغة، ذو أسلوب ونظم معجز، أب نعم، ولكن من الواجب ترجمة معانيه من أجل

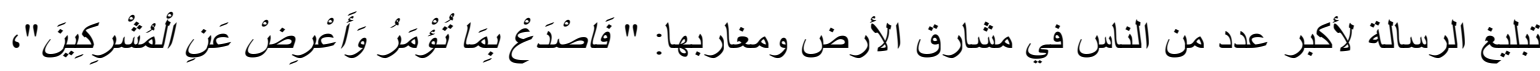
سورة الحجر، الآية 94، جاء تفسير هذه الآية في الميسر ـــمجع الملك فهد:" فاجهر بدعوة الحق التي أمرك الله

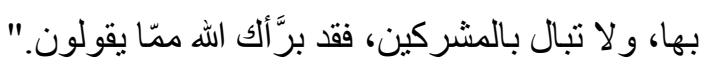




\section{المجلة الدولية لنشر البحوث}

International Journal of Research and Studies Publishing
المجلد الثاني - الإصدار التاسع عشر.

تأريخ الإصدار: 20 مايو 2021م

\section{ـ أهداف البحث:}

1- من المؤكد أن ما يهمنا من خلال كتابة هذا البحث هو تقديم منظور علمي في ميدان الترجمة وخصوصا الترجمة الدينية و التركيز على مجهود نرجمة معاني القر آن الكريح.

2- حيث، في البداية وبما أن ميدان الترجمة مرتبط بشكل وطيد بالعلاقات الاجتماعية الإنسانية، سنحاول تقديم تحليل للمشاكل المتصلة بالتعامل البشري على مستوى الثقافات و اللغات، وكيف أن رفض الآخر والتعامل السلبي الناجم عنه النه

$$
\text { يمكن أن يؤدي بالإنسانية الى عو اقب غير محمودة. }
$$

3- وسنركز على أهم الجوانب التاريخية التي أثرت على الانغلاق الذي عرفته الثقافة العربية والإسلامية المنبنقة عنها،

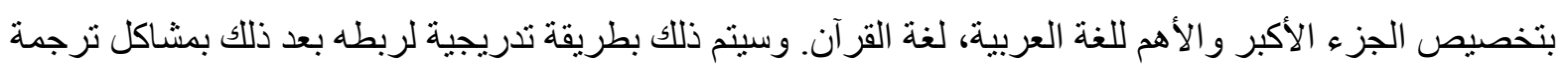

$$
\text { المعاني القر آنية في حد ذاتها و الحلول المقترحة لها من أجل الباحثين و المترجمين. }
$$

4- سنحاول ربط كلية عرض البحث بتوصيات في الموضوع، مؤكدين على وجوب ترسيخ وتوحيد كل مشاريع ترجمة القر آن الكريم و إرسائها على قو اعد وأسس علمية محضة مع احتر امها للمعايير الإسلامية في ترجمة الخطاب الإلهي

\section{المحفوظ بإذن الله بَّلة.}

5- ثم سنسلط الضوء على ضرورة دعم سبل انفتاح كل مجهود في الترجمة القر آنية على الإنجاز ات العلمية والتكنولوجية

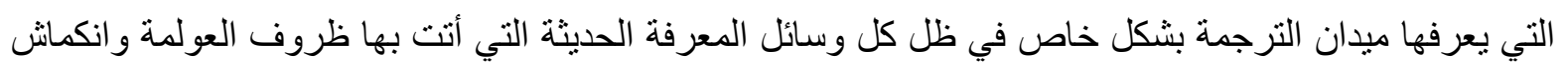

$$
\text { العالم الى قرية صغيرة. }
$$

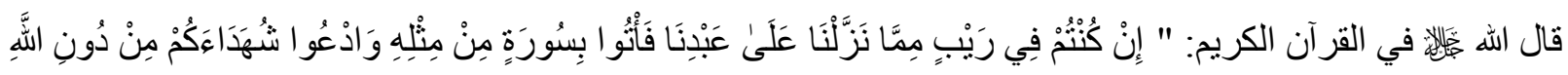

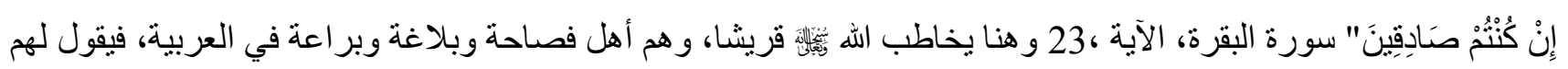

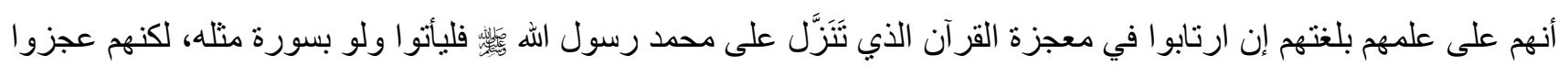

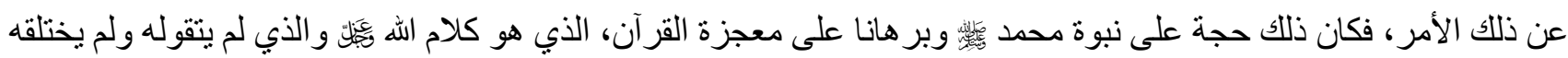

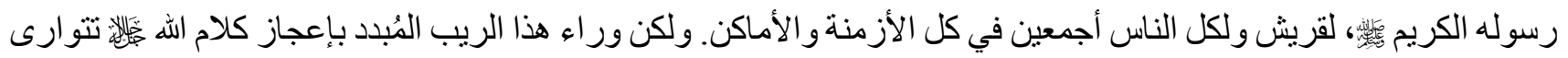

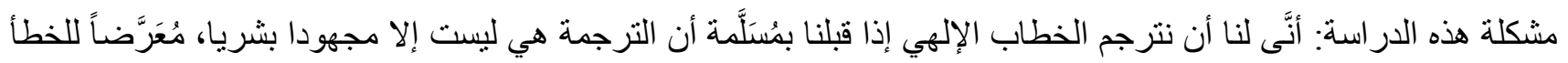

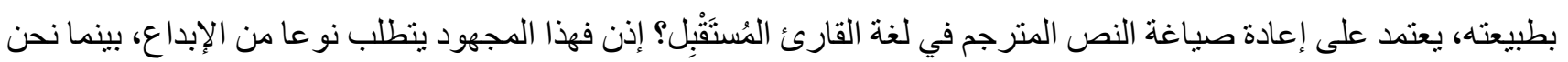

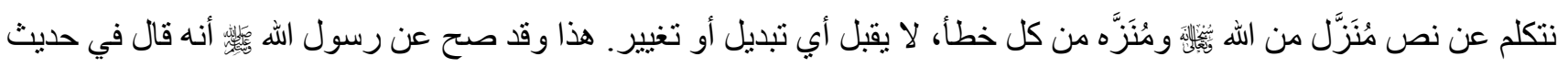

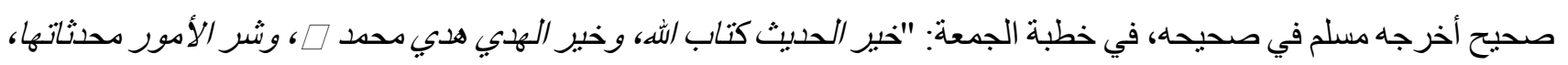
وكل بدعة ضلالة ". وأسند النسائي بإسناد حسن: "وكل ضلالة في النار "، وقال أيضا عليه الصلاة و السلام في الحديث الصحيح:

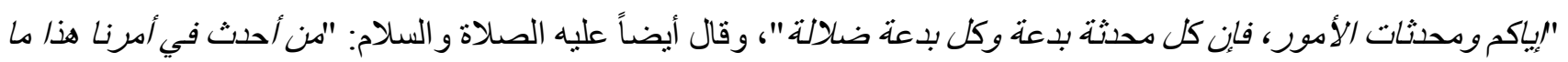
لبيس منه فهو رد " وقال عليه الصلاة والسلام: "من عمل عملًً لببس عليه أمرنا فهو رد " أخرجه مسلم في صحيحه.

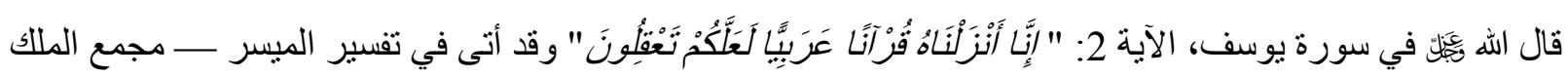

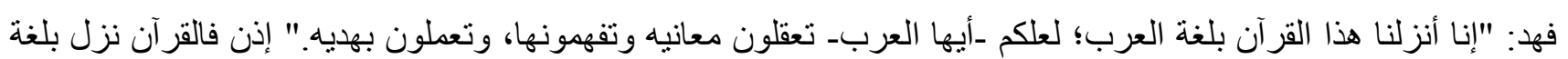

$$
\text { العرب على العرب ليعقلوهويتدبروه، }
$$




\section{المجلة الدولية لنشر البحوث}

International Journal of Research and Studies Publishing

ISSN: 2709-7064
المجلد الثاني - الإصدار التاسع عشر تأريخ الإصدار: 20 مايو 2021م

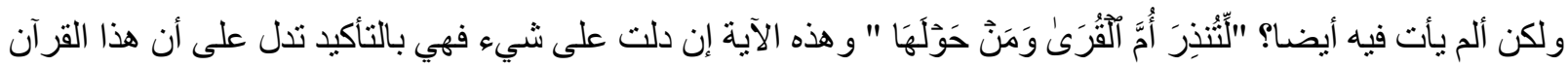
نزل على الرسول الكريم

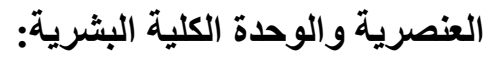

لقد أصبح مفهوم العُنصر البشري و العِرْق في منظور العلوم الحديثة وخصوصا علم الجينات، مفهوما متجاوزا مجردا من أي ثو ابت أو أسس علمية. حيث أمكن اليوم استنادا الى أحدث الاكتثافات في علم الجينات ومن خلال قر اعة الجينوم البشري أن يُبطُلَ مبدأ التقسيم العرقي وأن يُنْبَت بير اهين وحجج لان تقبل النقاش أنه لا وجود إلا لعنصر بشري واحد يجمع كافة البشر وأن

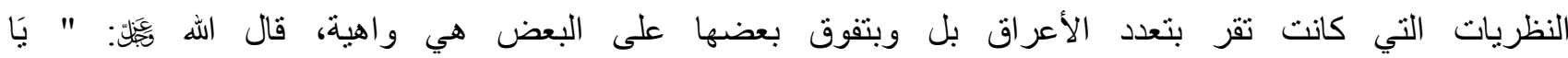

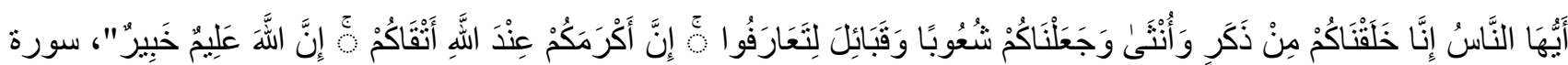

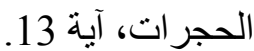

لقد تعايش الإنسان منذ القدم مع مفاهيم العنصرية والعرقية المسخرة أساسا من طرف إيديولوجيات قومية تعزز ثقافة الهوية و الانتماء عند الأفر اد و الجماعات لتبرير الانتهاكات من جر ائم و إبادات. لكن إذا درسنا عن قرب كل هذه التجاوزات الدر امية التي عرفها تاريخ البشرية لوجدنا أن هدفها الرئيس كان (ولم يزل) هو استعباد الجماعات المغلوبة والاستيلاء على الثروات، لأن "المال عصب الحرب"1 كما يقول المثل. أما من وجهة نظر الدين، فالديانات السماوية كلها لم تختلف حول تعريف الجنس البشري الذي يرتكز على مبدأ انتساب

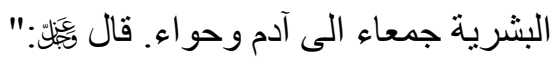

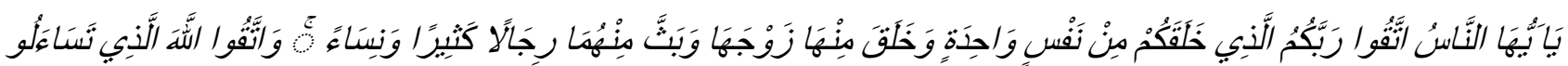

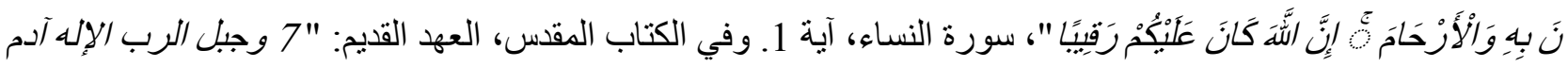

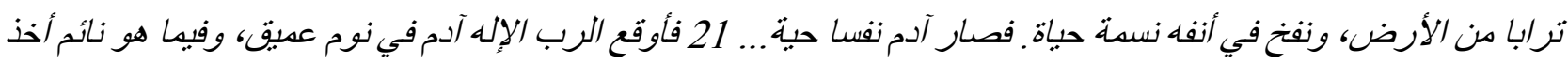

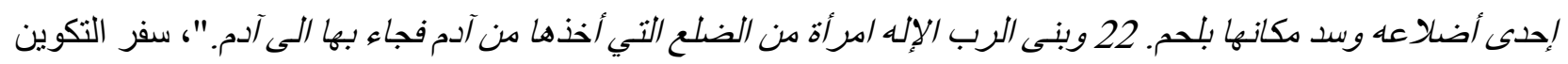
إصحاح 2: 22-21-7.

و هذه الفكرة بحكم تعريفها تؤيد المنظور العلمي الحديث، وتؤكد الأصل الإنساني الواحد الذي يجب على البشرية أن تلتف

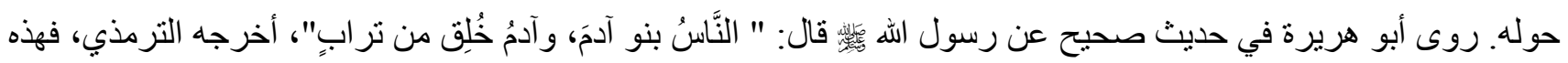
النقطة المشتركة بين العلم الحديث و الدين تستبعد كل الفروقات المبنية على الانتماء الإثني، الثكلي أو حتى الثقافي و اللساني، لأن

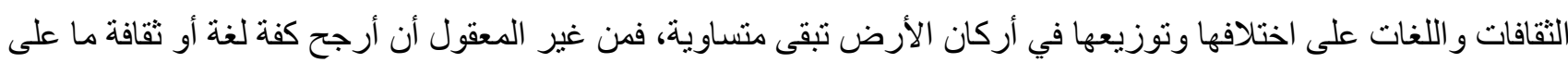
أخرى مستذر عا برؤية ما أو ذو ق لأنها حصيلة عملية ذاتية يصعب، بل يستحيل، إنباتها علميا.

1 "المال عصب الحياة": مثل لاتيني "Pecunia est nervus belli" يعود للخطيب الروماني سيسيرون، يعني أن المال هو الدافع الأساس للحروب. قياسا، بستعمل هذا المثل للتعليق على كل مشكل أصله وحله ماليَّان. 


\section{المجلة الدولية لنشر البحوث}

International Journal of Research and Studies Publishing
المجلد الثاني - الإصدار التاسع عشر

تأريخ الإصدار: 20 مايو 2021م

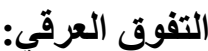

1-1

لقد بدأت المبادئ الفلسفية التي تنادي بعدم التساوي بين الجماعات البشرية تنتشر مع مطلع عصر النهضة الأوروبي، كمبدأ تعدد الأصول2 الذي نفى انحدار الجنس البشري من أصل زوج واحد وتبنى فكرة وجود أصول متعددة للإنسان ومن تم زعم بأن تعدد الأجداد نولد عنه تنوع، بل وفو ارق بين الجماعات البشرية.

في سنة 1859 نشر عالم الطبيعة الإنجليزي تشارلز داروين كتابه الثهير "أصل الأنواع"3 حيث وضع تصوره لمفهوم تطور الكائنات الحية حسب التغييرات العشو ائية التي نطر أ من جيل لآخر من |أجل التلاؤم مع المحيط الطبيعي. ولم يكتف داروين بتطبيق نظريته على الحيو انات غبر الناطقة بل أكد أن منظوره ينطبق على الإنسان كذلك بحكم انتسابه أساسا لجنس الحيو ان قبل كل شيء. هذه الدراسة أحدثت ثورة علمية بعد نشرها ونتجت عنها بطبيعة الحال مقاطعة وشرخ عظيم مع الفكر الديني الذي

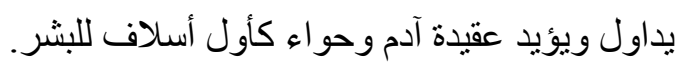

وفي نفس القرن أخذ بعض علماء الطبيعة والبيولوجيا وكذلك بعض علماء النفس على عاتقهم مهمة تصنيف وترتيب "الأعر اق" البشرية هرميا حسب معطيات لون البشرة، ملمس الشعر وحجم الجمجمة، الذي يعطي فكرة، على حد زعمه، على درجة الذكاء عند الجنس المدروس. ومن هنا تم الإقرار بدونية أعراق مقارنة بأخرى وطبعا تم وضع الإنسان الأبيض البشرة، الجنس الآري، في قمة هذا الترتيب الهرمي وتم اعتبار عرقه كأصل للإنسانية وأن كل الأعر اق الأخرى باختلاف ألو انهاو أثنكالها ما هي إلا تحولات فيزيولوجية جاءت نتيجة لفعل عوامل الزمن والتنقلات البشرية عبر أنحاء الأرض.

من فكرة التفوق العنصري انبثقت في بعض الأوساط العلمية فكرة أفظع تنبني على ضرورة تجويد الجنس البشري بتطهيره من العناصر التي تعتبر دونية ومتخلفة. الفرنسي آرتور دو جوبينو ألف كتابا في هذا السياق ونشره سنة 1853 تحت عنوان "مقال حول عدم الدساواة بين الأجناس البشرية" 4 أكد فيه على تفوق الجنس الآري (الهند-أوروبي) وضرورة الخضوع لمفهوم الانتقاء الطبيعي لمجموعات بشرية أقوى على حساب من هي أضعف. هذه الدراسة ودر اسات أخرى تلتها كان لها تأثير كبير

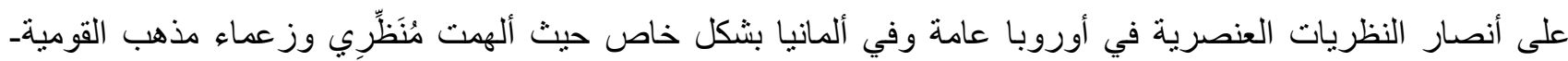
الاشنر اكية و الفكر الفاثي و النازي. بالتالي فالملاحظ هو أنه انطلاقا من أفكار ودر اسات قد تبدو هينة في الوهلة الأولى تطورت التأويلات و التعليلات ليبدأ البعض في المطالبة بنقاء وصفاء عرق ما على حساب الآخرين،

2 تعدد الأصول: (polygénisme) بمعنى أن البشر لا ينحدرون من نفس الأصل. استخدمت هذه النظرية كمقدة لنظرية نراتبية الفصائل البشرية لتبرير

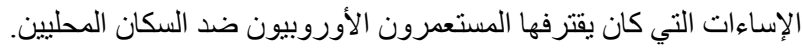

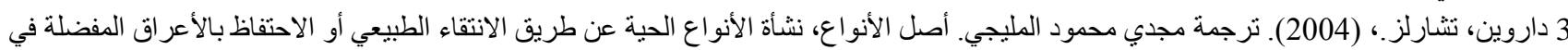

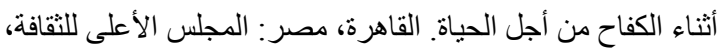
4 مقال حول عدم المساو اة بين الأجناس البشرية:

Comte de Gobineau J.-A., 2015, Essai sur l'inégalité des races humaines, Crissier, Suisse : FB Editions 


\section{المجلة الدولية لنشر البحوث}

International Journal of Research and Studies Publishing
المجلد الثاني - الإصدار التاسع عشر.

تأريخ الإصدار: 20 مايو 2021م

ISSN: 2709-7064

فتخرج تللك المطالبة من وراء ستار البحث العلمي الى الجهل المقنع لتتمأسس وتظهر للعالم في صورة در امية، صورة وصمة لا زالت تلطخ تاريخ بعض الأفر اد والجماعات وجرح غائر لا يلتئم في جسد آخرين: نظام مبني على الانتماء العرقي وحكم العنصرية.

\section{الميز اللغوي:}

\section{1-2 القومية العربية:}

لقد ابتدأ وعي العرب بانتمائهم لما يشبه كتلة واحدة، أي كجماعة مختلفة عن غير ها، قبل ظهور الإسلام. حيث ظهر هذا الوعي بضرورة الوحدة ردا على محاو لات الغزو التي كانت تأتي من الجيران المباشرين لجزيرة العرب: الروم البيزنطيون في

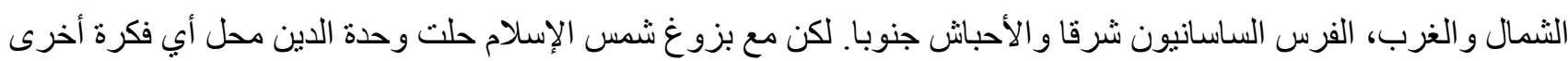

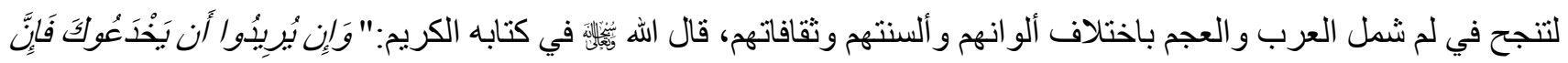

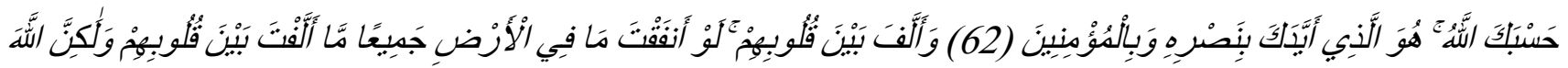

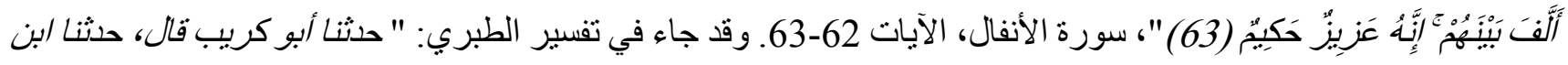

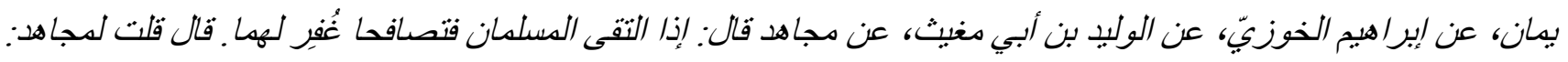



لكن "القومية" العربية بالمعنى الحديث للاصطلاح، أي الثعور بالانتماء للعنصر العربي المبني أساسا على الوحدة اللغوية وضرورة جعله رابطا أساسا بين الثعوب العربية لم تولد الا في القرن التاسع عثر. حيث جاءت هذه الولادة كردة فعل على تدهور حال الإمبر اطورية العثمانية وأحو ال بلاد الإسلام، أو ما كان بطلق عليه أنداك "الأمة الإسلامية"، الخاضعة لحكم السلطان، أمير المؤمنين. بحيث أن الدين الإسلامي، بشكل عام، كان هو المقياس الأساس في التقسيم السياسي والمحدد الرئيس للانتماء

بداية كانت مطالب القوميين مُقتصرة على بلاد الثشام ومحصورة في الإصلاح داخل مُكونات الدولة العثمانبة، و المُناداة باعتماد اللغة العربية في التعليم والإدارات المحلية. ثم تكاثرت بعد ذللك المشاعر القومية تزامنا مع انهيار قوة السلطان و الإمبر اطورية العثمانية في بدايات القرن العشرين وازدياد أطماع الدول العظمى في احتلال المنطقة العربية بتأجيج نير ان الكره للأتر الك في أنفس العرب. وقد ظهر العديد من المفكرين والكتاب العرب الذين تبنو انظرة المُنَظِّرين الغربيين للقومية وبدأوا يبشرون بميلاد المُقومات الأولى للقومية العربية في العالم العربي. نجيب عازوري كان من بين هؤلاء الرواد في كتابه "يقظة الأمة العربية"5، الذي كتبه لسبب ما باللغة الفرنسية، والذي دعا فيه إلى تحدث عنها المفكرون القوميون الغربيون مثل أرنست رينان في كتابه الثهير "ما هي الأمة؟"6 الذي وجد أنداك انفصال العرب عن سلطة العثمانيين وتأسيس دولة عربية خاصة بهم،

5 يقظة الأمة العربية: - n

Azoury Negib, Le réveil de la nation arabe, Kessinger Publishing, 2009.

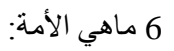

Renan Ernest, Qu'est-ce qu'une nation ? République des Lettres, 2012. 


\section{المجلة الدولية لنشر البحوث}

International Journal of Research and Studies Publishing

ISSN: 2709-7064
المجلد الثاني - الإصدار التاسع عشر

تأريخ الإصدار: 20 مايو 2021م

لأنه اعتبر أن للعرب كل مقومات الأمة التي صدى كبير الدى الطلاب و المفكرين العرب و أثر على أفكار هم بالغ التأثير، خاصة أن رينان، اعتبر أن اللغة والثقافة هما المكونتين الرئيستين لمفهوم القومية. وقد كان للإنجليز دور مهم في دعم بدايات القومية العربية لكسر شوكة الدولة الإسلامية وتكريس فكرة "فرق تسد"، حيث قاموا من خلال توماس إدوارد لورنس، الجاسوس البريطاني الذي اثتنهر بانخر اطه في حياة العرب وعُرف بلقب "لورنس العرب"، بتحريض الثريف حسين على القيام بثورة عربية ضد العثمانيين. فتم النصر للقبائل المو الية لفيصل ابن الثريف حسين. لكن رغم ذلك فثلت القومية العربية في إقامة المملكة العربية المبتغاة بقيادة الملك فيصل الأول، وفي المقابل نم لبريطانياو حلفائها مر ادهم ونجحو ا في تمزيق أمة الإسلام الى دويلات تعتبر محيطها الجغر افي وطنا وتز عم بأن لها خصائصها الثقافية التي تتفرد بهاو تذود عنها.

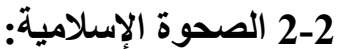

هذا المقال هو عبارة عن محاولة لكثف "النقاب"، إن صح القول ودون اللعب على الكلمات، عن نوع من أنواع العنصرية الذي لا يقل خطورة عن الأنواع الأخرى، لأنه، أولا، موجود منذ زمن طويل، ثانيا، لأنه يقرن في كثير من الأحبان بالمقدس و العقيدة، مما يضفي عليه نوعا من التأصيل الديني الذي لا يقبل النقد والمناقشة عند المتدينين، المتشددين منهم على وجه الخصوص. فالدين له خصوصية تجعل أنه يجذبنا الى المركز فيفقدنا هويتتا الإنسانية الاجتماعية التي تجعلنا نشع الى الخارج، فنفقد بالتالي المعرفة السبيية ومن تم نفقد قدرتنا في الحكم على الأشياء بطريقة عقلانية. لأن الدين أو الديانات باختلافهاو اختلافاتها

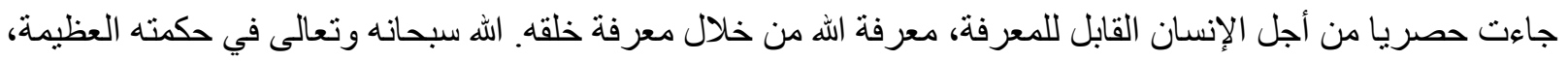
و هنا أختص بالذكر أهل الكتب السماوية بصفة عامة، أر اد من الإنسان أن يتفكر وأن يطلب المعرفة من أجل الوصول الى

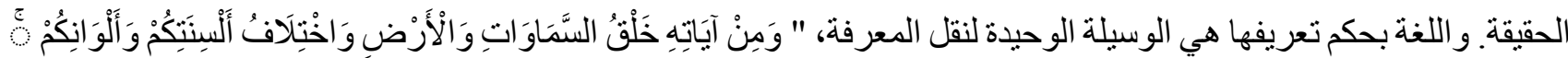

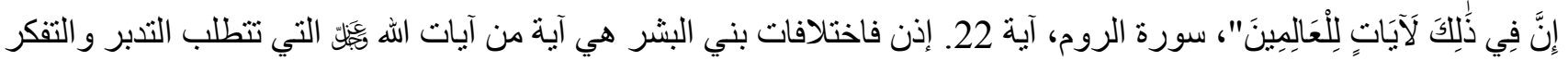
من أجل المعرفة وهي موجهة للناس أجمعين باختلاف انتماءاتهم "إن في ذلك لآيات للعالمين". بعد فثل القومية العربية في سد الفر اغ الوحدوي الذي أنتجه سقوط الدولة الدينية و الثتات الذي أصساب "الأمة الإسلامية"، ظهرت في مجتمعاتنا تجليات الغياب الديني في سياسة أمور الناس، نظر اللتجاذبات الجيوستر اتيجية المتولدة عن الحرب الباردة بين المعسكر الثيوعي السوفيتي و المعسكر الر أسمالي الغربي و أيضا كنتيجة حتمية للهز ائم المتو الية التي لحقت بالجيوش العربية على يد جُوَيْشِ الكيان الصهيوني. ابتداء من سبعينيات القرن الماضي، وبشكل أقوى عن ما مضى، ارتبط مصطلح "الصحوة الإسلامية" بكل أنواع "إعادة أسلمة" المجتمع العربي من طرف الأحز اب و المنظمات ذات المرجعية الإسلامية و التي تمارس الإسلام السياسي، سواء تللك التي

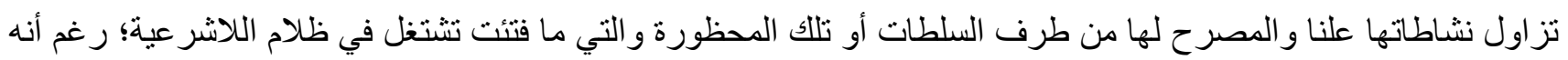
يمكن الجزم بأن السلطات الممثلة غالبا في حكومات تتبنى الفكر القومي العلماني العربي (البعثية والناصرية، والقذافية) كانت دائما حذرة اتجاه الأولى وكانت تشن حربا شعو اء على الثانية، 


\section{الهجلة الدولية لنشر البحوث}

International Journal of Research and Studies Publishing
المجلد الثاني - الإصدار التاسع عشر

تأريخ الإصدار: 20 مايو 2021م

ISSN: 2709-7064

نظر ا للخطاب و النهج السياسيين اللذان كانت تعتمدهما تلك التنظيمات، حيث أنه في غياب مرجعية إسلامية حكومية ذات مصداقية وفثل الحكومات في تقديم بديل عن ما كان ينظر إليه كأمجاد الماضي الإسلامي، أصبح المجتمع في أغلبية خطيرة يشعر رويدا رويدا بالانتماء لهذا الفكر الئحدث. فلاحظنا الظهور المكثف لحركات يمكننا نسميتها "بالإسلامَوِيَّة"، لممارستها إغر اء إيديولوجيا على الجماهير المتعطشة لبديل للقومية العَلمانية. وقد جاء ذلك من خلال العمل السياسي بطريقة غير واضحة المعالم أي بدون برنامج سياسي يبين نواياها المستقلية العملية اتجاه الأمة. و الهدف الأول لهذه التنظيمات، كما يمكن أن يستوضح عنه أي باحث في الثأن السياسي العربي، هو تعبئة الجماهير من أجل خدمة مصالحها. "الإسلاموية" تعني الثعبوية التي تتخذ

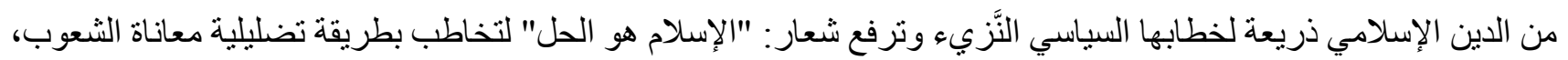
وفي نفس الوقت فهي تتخذ من الدين حجة لمواجهة خصومها واستبعاد كل من لا يناصر أفكار ها من ساحة الحل السياسي، بل هنالك من يمضي أبعد من ذلك - و هم للأسف ليسوا بقلة داخل هذا التوجهـ فيضع المنافس و المناهض و المناوئ في سلة واحدة

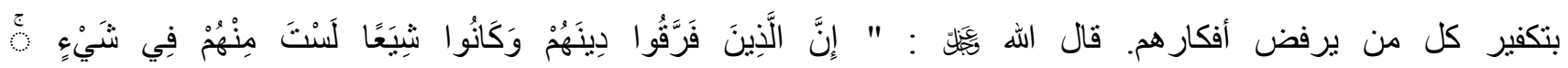



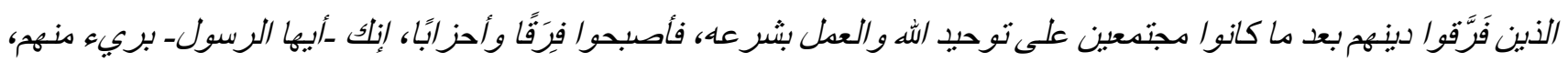

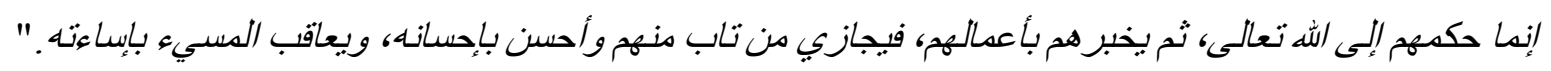

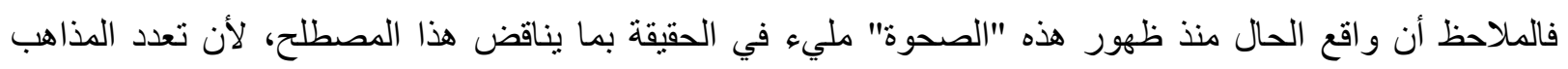
و الطو ائف و الفرق بين شيعة وسنة وصوفية وسلفية وتكفيرية و إخوان وقاعديين وداعشيين، إلخ.. جعل منها مر ادفا لفتنة شاملة أبطلت مبادئ الوحدة التي تدعو لها، في ظاهر الأمر.

لقد لمسنا عند مناصري هذه الصحوة نظرة لا تقل دونية وتحقير اللآخر عن مثنائهم الموالين لأفكار القومية والعرقية، نظرة استعلاء للثقافة بشكل عام وللثقافات واللغات "الأعجمية" بشكل خاص، رغم أن أغلب من يدينون بالإسلام في أنحاء

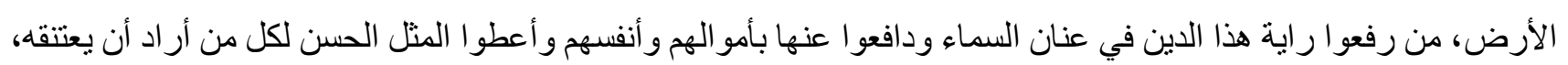

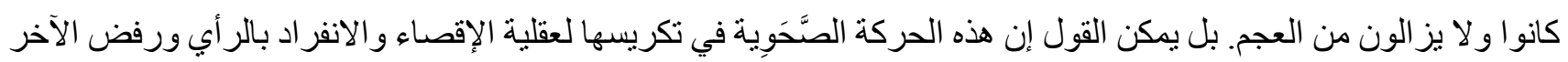
و إن كان من نفس العقيدة، أتت بقر اعة جديدة للدين من خلال تقديس اللغة العربية اعتباطا و اعتبار ها بدون علة جائزة أول لغة تكلم بها سبدنا آدم و أنها لغة الآخرة، أي لغة الحساب ولغة أهل الجنة. روى الطبر اني في الأوسط عن أبي هريرة رضي الله عنه قال:

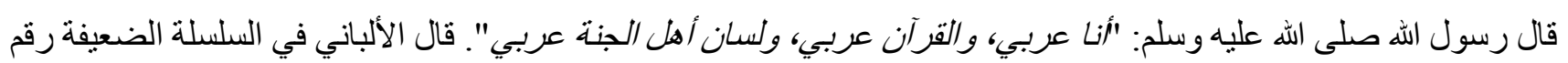
161 : موضوع. (161

وسُئل شيخ الإسلام ابن تيمية رحمه الله: بماذا يخاطب الناس يوم البعث؟ وهل يخاطبهم الله تعالى بلسان العرب؟ وهل صح

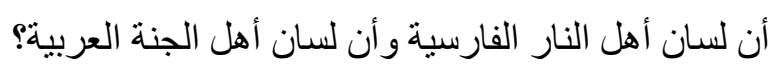

فأجاب: " الحمد لله رب العالمين لا يُعلم بأي لغة يتكلم الناس يومئذ، و لا بأي لغة يسمعون خطاب الرب جل و علا؛ لأن اله

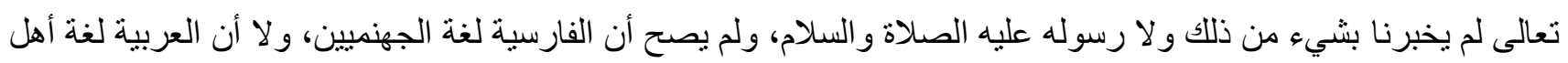
النعيم الأبدي، و لا نعلم نز اعا في ذلك بين الصحابة رضي الله عنهم، بل كلهم يكفون عن ذلك لأن الكلام في مثل هذا من فضول القول... ولكن حدث في ذللك خلاف بين المتأخرين، فقال ناس: يتخاطبون بالعربية، وقال آخرون: إلا أهل النار فإنهم يجيبون بالفارسية، و هي لغتهم في النار. وقال آخرون: يتخاطبون بالسريانية لأنها لغة آدم و عنها تفرعت بـت اللغات. 


\section{المجلة الدولية لنشر البحوث}

International Journal of Research and Studies Publishing

ISSN: 2709-7064
المجلد الثاني - الإصدار التاسع عشر

تأريخ الإصدار: 20 مايو 2021م

وقال آخرون: إلا أهل الجنة فإنهم يتكلمون بالعربية. وكل هذه الأقوال لا حجة لأربابها لا من طريق عقلٍ ولا نقل بل هي دعاوى عارية عن الأدلة والله سبحانه وتعالى أعلم وأحكم "، (ابن تيمية، مجموع الفتاوى، 299/4، 1995)

$$
\text { 3-2 - 2 - 2 الميز اللغوي وتبليغ الرسالة: }
$$

الميز بين الناس في اللغة هو ظاهرة تجلت منذ القدم، وخير مثال على ذلك الخطاب الديني التور اتي الذي جسد هذا النوع من العنصرية من خلال رواية البلبلة التي تصور تتوع ألسنة البشر كانتقام إلهي منهم لخوفه منهم، و العياذ باله من هذا الوصف، وتضفي نوعا من القدسية على اللغة الموحدة: "1) وكان لأهل الأرض كلّها لغةٌ واحدة وكلام واحد.2) فلمّا رحلوا من المشرق وجدوا بقعةً في سهل شِنْعار، فأقاموا

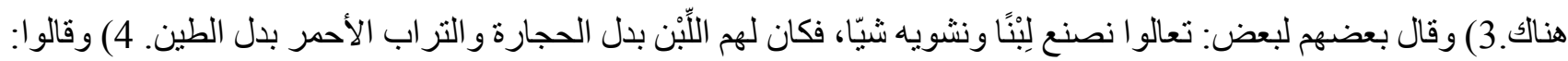

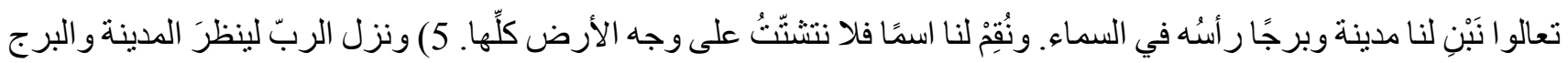

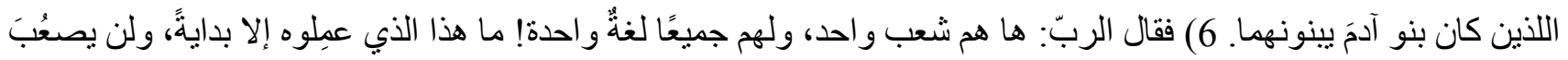

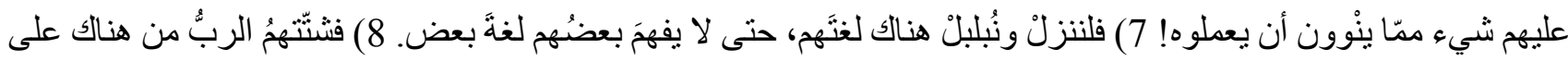

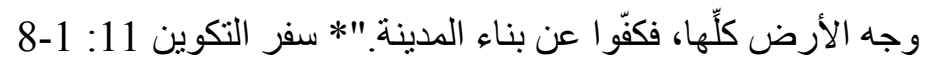
أما بخصوص الدين الإسلامي فالقرآن جعل من اختلاف ألسنة البشر وتتوعها آية من آيات الله تعالى، أي معجزة من



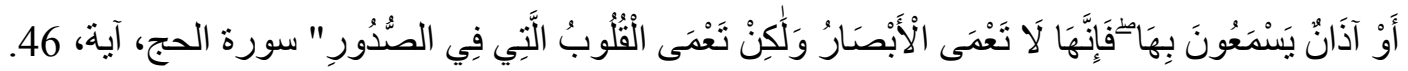
و المعنى في الاختلاف و التنوع أنه على كثرة الناس وتباينهم، رغم أن الأصل واحد ومخارج الحروف واحدة لا نتشابه الأصوات و لا طرق الكلام، والله فئلِّة قََّر ذلك الاختلاف لكيلا يقع التشابه فيحصل الاضطر اب بين خلقه. لقد بُعث الرسول

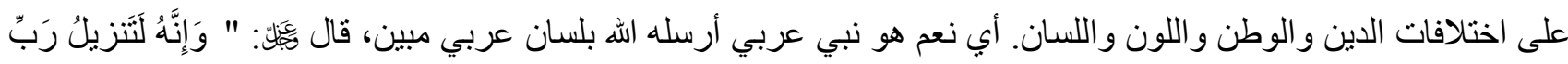

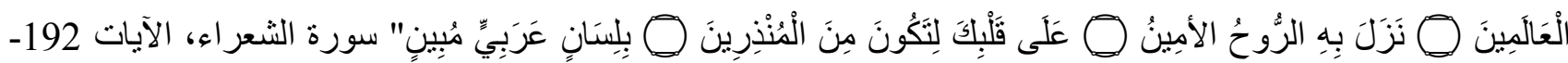

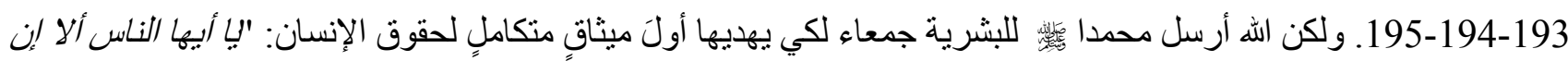
ربكم واحد، وإن أباكم واحد، ألا لا فضل لعربي على أعجمي، ولا لعجمي على عربي، ولا لأحم على أسود ولا أسود على

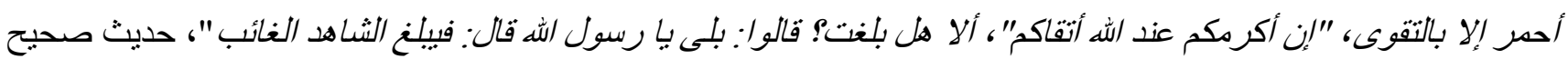
حدثنا به الألباني في شرح الطحاوية، و هناومن خلال خاتمة هذا الحديث الثريف يمكن ملاحظة التوكيد على أهمية تبليغ الرسالة.

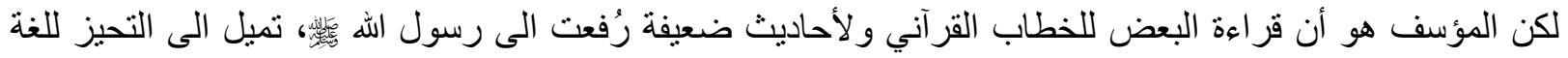

العربية، مانحة إياها طابعا قوميا يصغر من حجم عالمية الرسالة التي أتى بها محمد ابن عبد الله التحيز اللغوي كان دائما نتيجة لأسباب عرقية صِرْفه، حيث كان العرب ومنذ القدم يتفاخرون بلغتهم ويتحيزون لهاويتباهون بها بينهم وأمام غير هم من الأقو ام الى درجة أنهم أطلقو ا على كل الثعوب الأخرى إسم "العجم"؛ أنى في معجم المعاني الجامع:

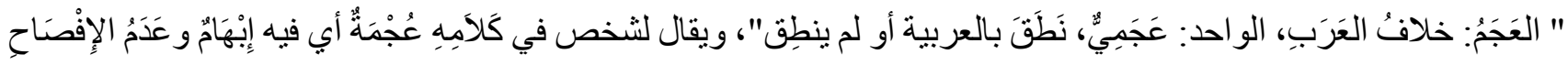


وفي هذا نوع من الاحتقار للشعوب الأخرى لأنه أنى في نفس المعجم أن العجماء هي البهيمة وأن الأعجم هو الأخرس عند

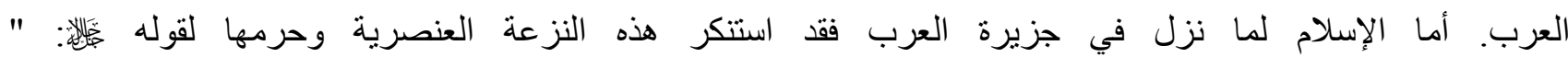

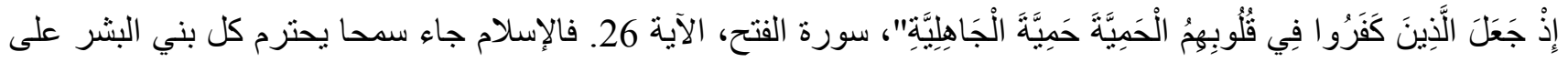
اختلافهم ولم يجعل التفاضل بينهم بالعرق أو باللون أو بالثقافة أو اللغة ولكن بالتقوى فقط: "إن أكرمكم عند الله أتقاكم". إن هذاء

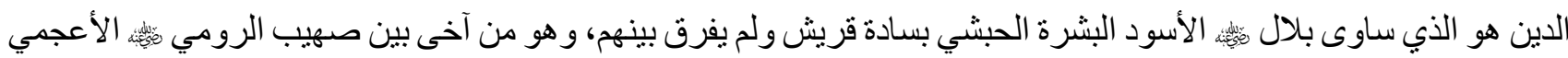
مع المسلمين العرب دون تمييز ولا تفضيل. وقد اعتبر النبي ئس أن كل من يدعو للعصبية أيا كان نوعها فهو خارج عن دين الله

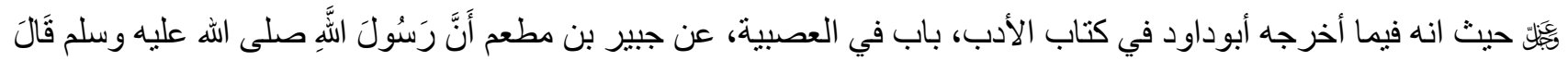

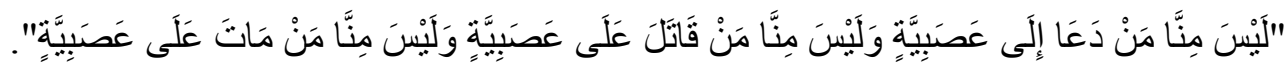

لكن، وللأسف، لقد جعل بعض الغُلاة للغة فقهاومن فقه اللغة أداة للغلو والانغلاق و التقوقع، أقصى غاياته الافتخار بالعربية بطريقة مبالغ فيها، بإجلال السلف من شعر اءها وأدباءها واعتبار ها معجزة إلهية على الرغم من تو اجدها قبل نزول القر آن الكريم

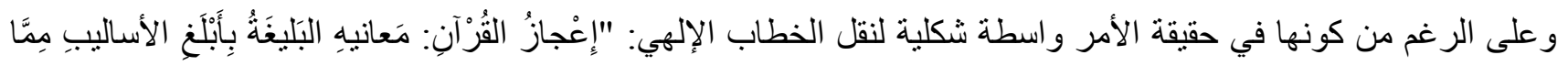

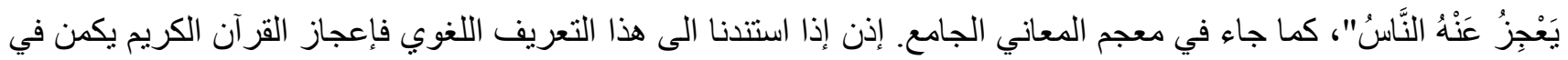
الخطاب نفسه وليس في أداته و إلا فلم لا نمنح العبرية والأرمية و السريانبة صفة الإعجاز لكونهن أيضا أدوات لغوية خاطب بها



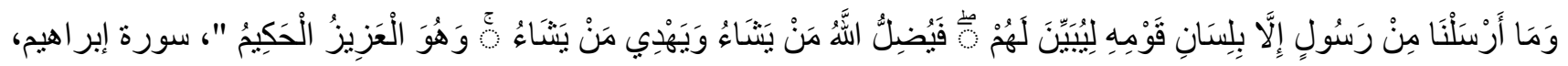

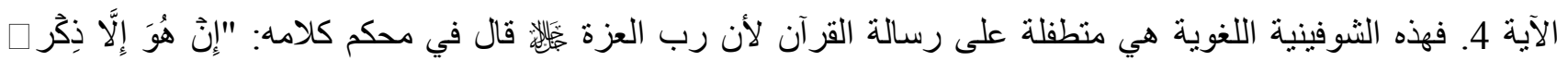


عظة للناس أجمعين ينذكرون به ويهندون."

\section{4-2 الاعوة الى الله وكونية الرسالة:}

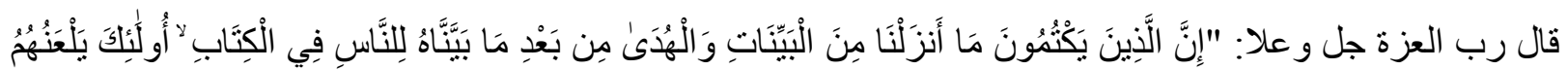

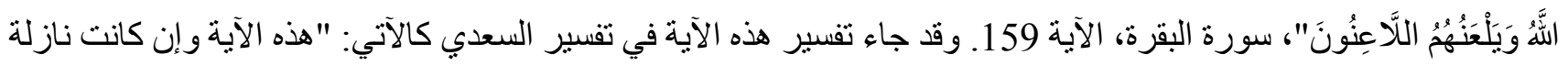

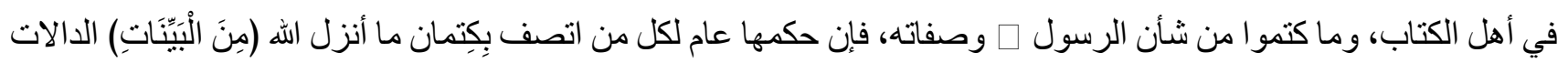
على الحق المظهرات له، (وَالْهُدَى) و هو العلم الذي تحصل به الهداية إلى الصر اط المستقيم، ويتبين به طريق أهل النعيم، من

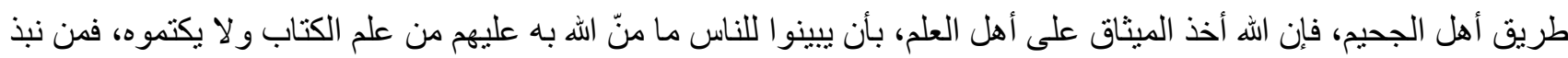

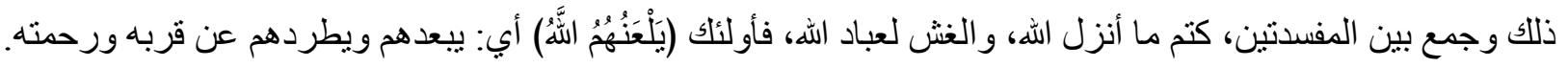


من رحمة الله، فجوزو ا من جنس عملهم، كما أن معلم الناس الخير، بصلي الله عليه وملائكته، حتى الحوت في جوف الماء، لسعيه في مصلحة الخلق، و إصلاح أديانهم، وقربهم من رحمة الله، فجوزي من جنس عمله، فالكاتم لما أنزل الله، مضاد لأمر الله، مشاق الله، يبين الله الآيات للناس ويوضحها، وهذا بطمسها فهذا عليه هذا الو عبد الثديد." 


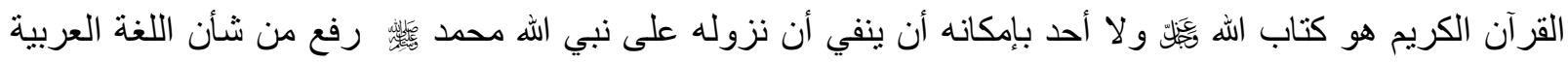

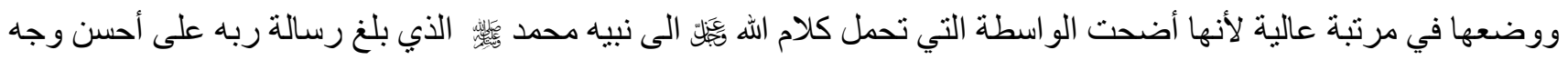
كما كان الحال بالنسبة لعبرية التور اة التي تنزلت على سيدنا موسى وآر امية و عبر انية الأناجيل على لسان سيدنا عيسى.

لكن هل وققت الدعوة الى الله تعالى عند الرسول الكريم

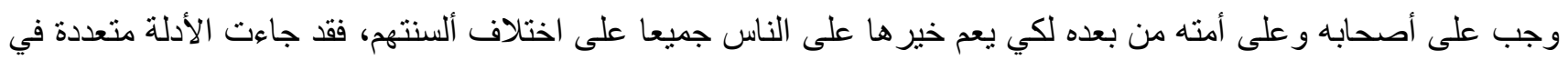

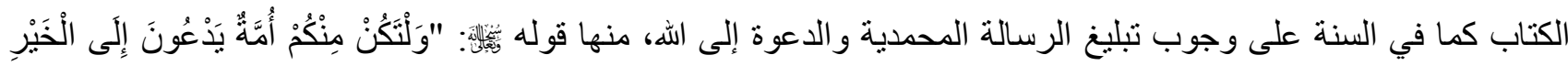

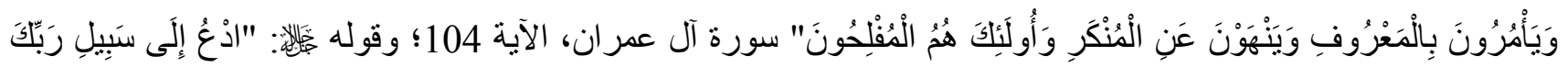

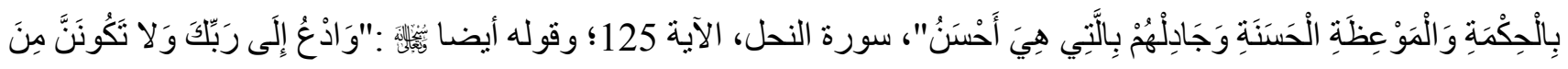

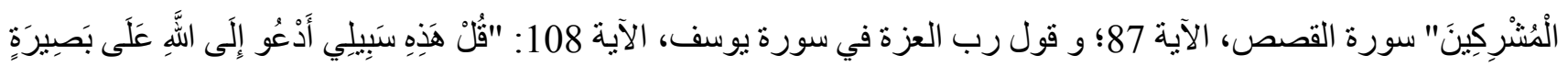
أَنَا وَمَنِ انََّعَنِي". فقد أمر الرسل وكذلك من اتبعهم بدعوة الناس إلى نوحيد الله وطاعته بالإنذار من هول عذاب الله لمن عصاه

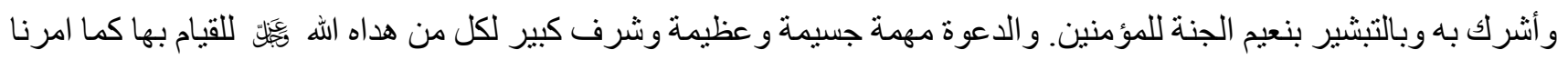

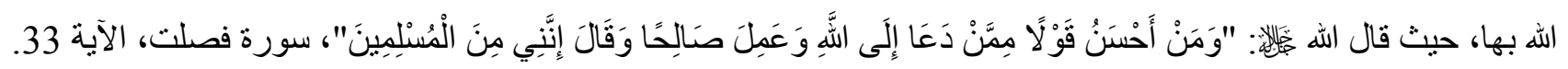

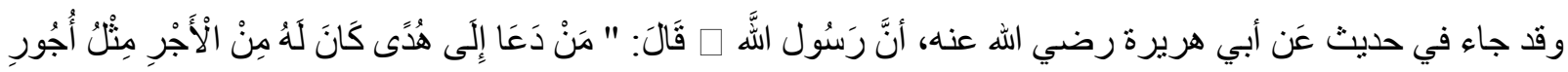

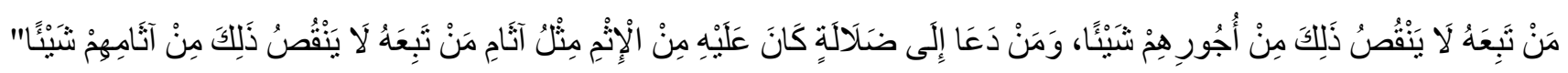

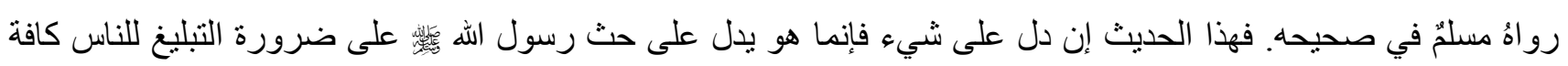
وأجر الدعوة لله، فالداعي إلى الله يجري لله ثواب من اهتدى بدعوته. وجاء في صحيح مسلم وغيره من حديث أبي مسعود الأنصساري قال رسول الله

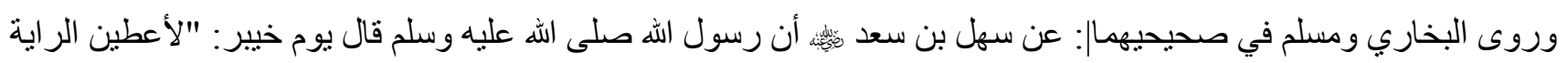
غداً رجلاً يفتح الله على يديه"، قال: فبات الناس يدوكون ليلتهم أيهم يُعطاها، فلما أصبح الناس غدوا على رسول اله صلى الله عليه وسلم كلهم يرجو أن يعطاها، فقال صلى الله عليه وسلم: "أين علي بن أبي طالب مِّئ. ؟"، فقالو ا: يشتكي من عينيه يا رسول

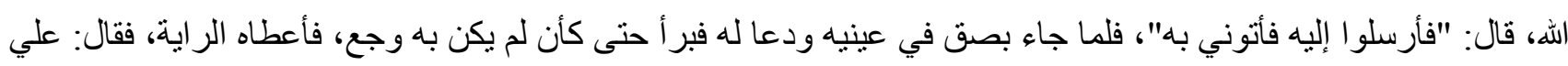

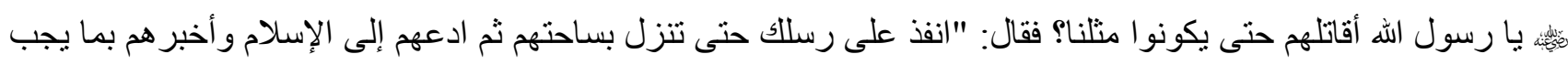


بن أبي طالب رضي الله عنه تبين لنا بجلاء حرص النبي عليه الصلاة والسلام على تحقيق الرحمة بين الناس جميعا على اختلافهم

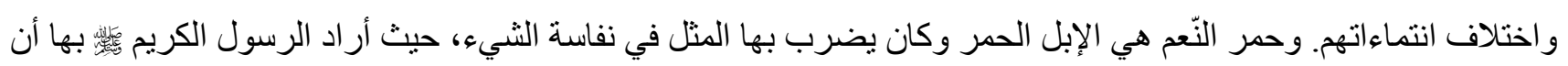

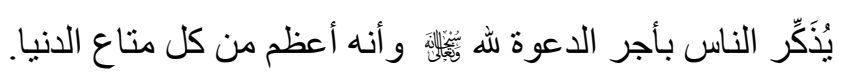
قال شيخ الإسلام ابن تيمية رحمه الله في الفتاوى: "ثبوت أحد الضدين يستلزم نفي الآخر". من هنا وبعد تلاوة كل هذه

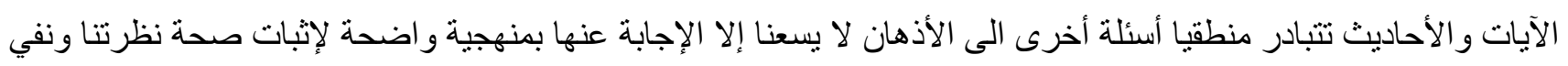

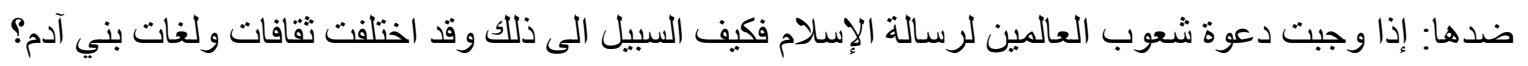


إذا كان الإسلام يدعو بصريح العبارة الى التدبر و التفكر في خلق الله أب أنه يدعو الى اتباع سبيل المعرفة ونهل العلم بشتى أنو اعه، قال الله

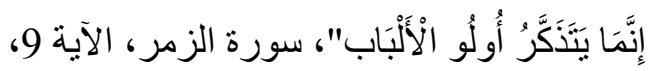



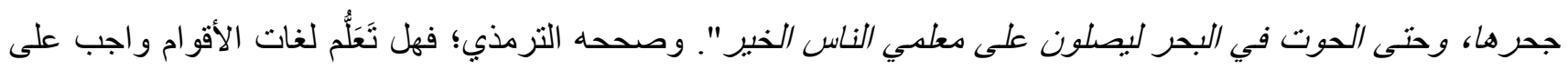


ربما، لتبرير هذا السؤال وجب علينا قبل كل شيء أن ننطلق من هذه المسلمة عند بعض أُصوليّيّي اللغات و التي تفبد أن "النص المترجم لا بمثل إلا بديلا رديئا للنص الأصلي": منطقيا وانطلاقا من هذا الجملة، لا يمكن للجواب إلا أن يأتينا بسهولة ووضوح: لا شك أنه سيتعذر علينا ان نضع ضرورة الترجمة دائما في موضع الريبة بالانزواء في نظرة متطرفة عقيمة تقدم الجهل بالثقافات الأجنبية والديانات السابقة للإسلام، و ربما اللاحقة أيضا، كإقصاء لمجهود أو لهدف قيل فيل عنه أنه غير مثالي، مقارنة بقسية الأصل، فنقع في التناقض الفكري: الترجمة "ضرورة تافهة". لأنه يجب أن نعترف يوما ما أن المجهود الترجمي و الترجمات كنتيجة له يُكَِّّنان حقلا فكريا خصبا لكل التوجهات العلمية الدينية منها و الدنيوية. الترجمة هي عملية نحاول من خلالها الربط بين البعيد والقريب فهي تمثل في نفس الوقت تباعدا عن الأصل وتقريبا له و هنا يكمن سر مز اولتها، فهي كشعرة معاوية إذا مدت وجب إرخائها وإذا أرخيت وجب مدها. و الإنسان عادة لا ينقل إلا الفكرة التي هو مقتنع بها ليضع نفسه في حيز ثقافي مشترك مع الآخر. إذن فهذا الجهد يجعلنا نندرج في فكرة العطاء ونبتعد عن أفكار العداء، داخل ما يمكن أن نسميه بيناو احدا تظل أبو ابه مفتوحة على مصر اعيها لكل عضو جديد؛ خصوصا إذا تعلق الأمر بترجمة نص مقس أو لغة تتسب لها القسية، حيث ينولد لدينا سلوك يشجع على التفكر و التدبر في هذا الغموض الذي يميز علاقة البعيد بالقريب و المنو اجد في صلب الجهد الترجمي. للأسف كثبر هم من يظنون أن عملية الترجمة، قبل أن تكون خيانة للنص وللغة المنبع، كما يقول المثل الإيطالي الثهير "Traduttore, traditore" أي "الترجمة خيانة" (و هنا اعتمدت عن قصد نرجمة لمعنى المثل، حتى يكون النص الهدف أكثر بيانا للمتلقي العربي ومناسبا في تركيبه للغة الهدف)، هي أيضا عبارة عن |استيلاء على المجهود الفكري و الثقافي في مصدره

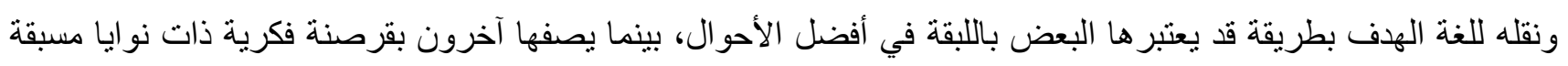

ولكن هناك سؤال يقى محير ا أكثر بالنسبة لمؤيدي الترجمة، لماذا احتقر العرب الترجمات الدينية والقرآنية من العربية



\section{5-2 الاستثراق والترجمة من العربية:}

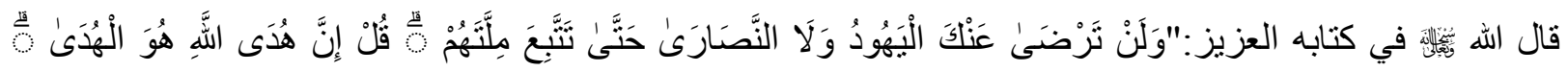

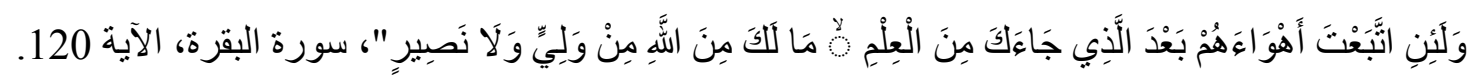




\section{المجلة الدولية لنشر البحوث}

International Journal of Research and Studies Publishing
المجلد الثاني - الإصدار التاسع عشر تأريخ الإصدار: 20 مايو 2021م

ISSN: 2709-7064

إن الاستشر اق هو مشتق من كلمة "شرق" أي "مطلع الثمس" ومعناه لغة: طلب الثرق. إذن فكلمة "الاستشراق" تدل على علم يهتم بما يحتوي عليه الثرق من علوم ومعارف وثقافات وميزات حضارية. أما "المستشرق" فهو العالم الذي وهب نفسه للبحث و الاهتمام بما يتعلق بالثرق وما يضمه من علوم ومعارف في مجالات عديدة ومختلفة.

ومفهوم الاستشر اق يختلف عند العلماء والباحثين، حيث أبدى العلماء آراء متتوعة حول مفهوم الاستثر اق اصطلاحا: 1 ـقال الدكتور إدو ارد سعيد في كتابه "الاستشر اق": "إن لفظ الاستشر اق لفظ أكاديمي صرف، و المستشرق هو من يدرس

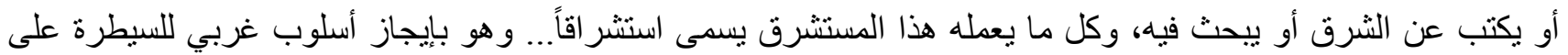

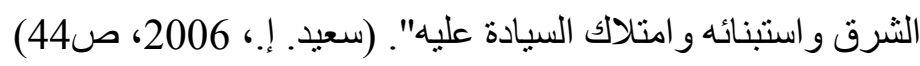
2-وفي رأي الدكتور محمد فتح اله الزيادي: "هو دراسة الثرق عموما ودراسة الإسلام والمسلمين خصوصا بقصد

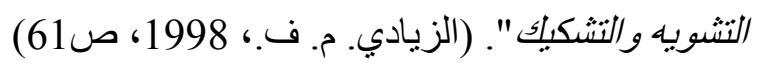
3 -وقال الدكتور شكري النجار: "إن الاستشراق هو أسلوب غربي لفهم الثرق والسبطرة عليه، ومحاولة إعادة توجيهه

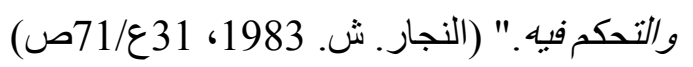

4ـ قال الدكتور محمود حمدي زقزوق: "الاستشراق هو علم الثرق أو علم العالم الثرقي، وكلمة "مستشرق" بالمعنى العام تطلق على كل عالم غربي يشتغل بدر اسة الثرق كله؛ أقصاه ووسطه و أدناه، في لغاته، و آدابه وحضارته و أديانه. ولكنتا هنا لا نقصد هذا المفهوم الو اسع، و إنما كل ما يعنينا هنا هو المعنى الخاص لمفهوم الاسنتر اق الذي يعنى "الدر اسات الغربية المتعلقة بالثرق الإسلامي في لغاته و آدابه وتاريخه و عقائده وتثريعاته وحضارته بوجه عام. و هذا المعنى هو الذي ينصرف إليه الذهن في عالمنا العربي الإسلامي عندما يطلق لفظ استشر اق أو مستشرق." (زقزوق. م. ح.، 1983، ص 24-25)

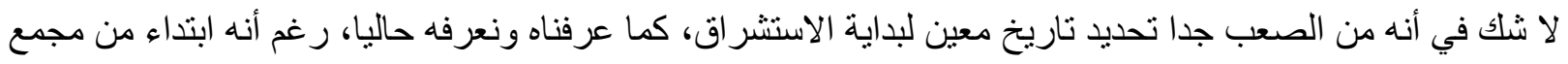
فيينا الكنسي في عام 1312م قُرِّر إنثاء عددٍ من الكر اسي المخصصة للغة العربية في عدد من الجامعات في أوربا. ولكن مع ذلك فليس هناك دليل قاطع يدل على البداية الحقيقية والمنظمة للاستشراق، حيث اختلف الباحثون في نشأته وبدايته. ربما ذلك بسبب اختلافهم حول مفهوم الاستشر اق أو بيان الأسباب و الدو افع للاستشر اق؟ ربما أن كلمتي "الإستشر اق" و "المستشرق" اللتين تحيلان على در اسة اللغات و الحضار ات الثرقية بطريقة حديثة ومنظمة ترجعان تاريخيا فقط الى القرن التاسع عشر. حيث يمكن اعتبار أن في هذه الحقبة تكونت العلوم المختصة عن الثرق. رغم أن جذور و أصول هذا العلم عميقة فقي فترة عصر النهضة مثلا، ظهرت أولى الميول لدر اسة اللغة العبرية ثم اللغات الثرقية الأخرى الضرورية للوصول الى أصول النصوص الإنجيلية. وفي القرن السابع عثر أيضا، كانت البحوث المجر اة من طرف الغرب عن الثرق لا تتعلق بمسألة الهيمنة بقدر ما كانت تمثل رغبة الأوروبيين في التعرف على أصولهم الدينية في إطار جو تنافسي عقدي. فتكو نت بذلك ثقافة عن المشرق تجمع بين الرغبة في معرفة الأصول الدينية و الثقافية الأوروبية وإر ادة إرساء سيطرة ومشرو عية داخل الصر اعات المندلعة بين الكاثوليك و البروتستانت أي بين المنشقين داخل الحركات التي تأتت من الإصلاح من جهة والقوى المنافسة الأخرى داخل الكنيسة الكاثوليكية من جهة أخرى.

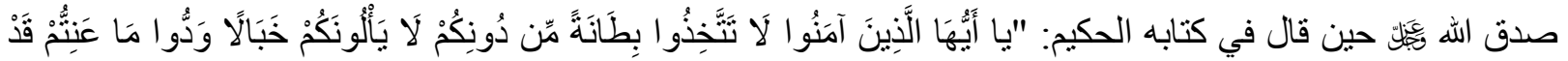

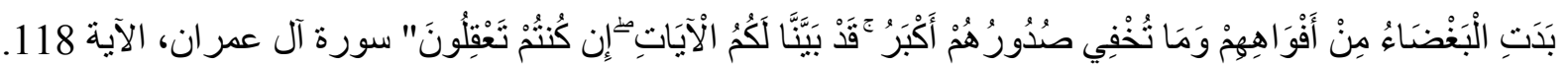




\section{المجلة الدولية لنشر البحوث}

International Journal of Research and Studies Publishing

ISSN: 2709-7064
المجلد الثاني - الإصدار التاسع عشر.

تأريخ الإصدار: 20 مايو 2021م

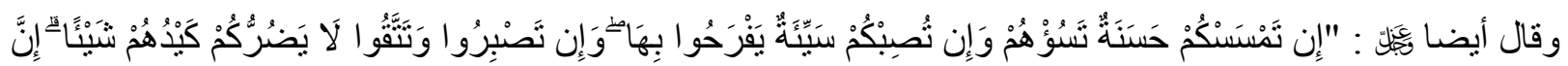

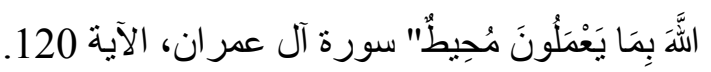
لقد تبين فيما بعد أن الاهنمام الكبير الذي أولته الدول الأوروبية للشرق عامة بكل مكوناته الثقافية والجغر افية وموارده الطبيعية وللمناطق ذات الأغلبية المسلمة منه بصفة خاصة كان هو نقطة البداية للحركة الاستشر اقية كما هي معروفة لدينا الآن، حيث تز امنت هذه البداية، كما أرخ لللك العلماء، مع انطلاق حملة نابليون في مصر. و انتشرت بعد ذلك الحركة في كل أنحاء الغرب جاعلة من در اسة الثقافة الثرقية في كل جو انبها أولوية كبرى في إطار التوسع الأوروبي وتطلعات الدول الأوروبية لبسط نفوذها على الثرق من أدناه الى أقصاه. إذن فالاستشر اق الذي يههناويعنينا هو ذلك التيار الفكري الذي يُعنى بفهم الثقافة الاسلامية و المسلمين خاصة ويضم كل الدر اسات الغربية التي تهتم بالعقيدة والسنة والثريعة و التاريخ الإسلامي، إلخ. لقد زود المستشرقون بلدان الغرب بمعلومات كثيرة عن الإسلام وحضارته، وعن عادات المسلمين، ولغاتهم، خصوصا اللغة العربية، حتى تيسرت لهم كل السبل لمعرفة مكامن قوة وضعف الأمة لينقضو ا عليها ويمزقوا جسدها. و لا مجال للثك في أن مهمة المستشرقين كانت دائما مرتبطة بالترجمة. فهدف المستشرق هو إعطاء تصور للعربي وللمسلم الثرقي (علما أن المشرق الإسلامي في نظرة الغرب المستشرق يمتد من بلاد المغرب الى تخوم المشرق الأقصى) وتقديمه في قالب حقيقة، تعرض هذا التصور أو التأويل الثقافي على المتلقي الغربي في لغته الأم أب اللغة الهدف بالنسبة للمترجم. وهنا نرجع مرة أخرى إلى هذا الر ابط الذي يجمع بين البعيد والقريب بفعل الجهد الترجمي، حيث يستورد المترجم المستشرق نصوصا غريبة عن ثقافته ثم يعالجها حسب منظوره الخاص، مغرضا كان أو نزيها، لينقلها الى اللغة المستقبلة. لهذا فإن التصور الغربي للتقافة والحضارة الإسلامية تجلى بشكل ملحوظ أكثر من خلال ترجمات المستشرقين للموروث الإسلامي في إطار تصور مبني في أغلب الأحيان على رؤية التميز و المثالية في كل ما هو أوروبي و الدونية فيما يتعلق بالإسلام و المسلمين، خصوصـا أن بدايات الاستشر اق تز امنت

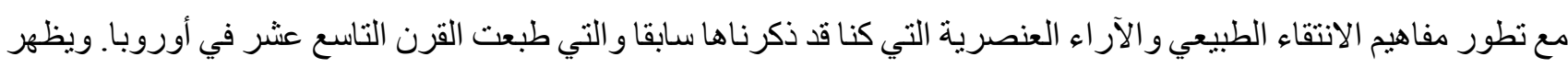
ذلك جليا من خلال جهل المترجم المستشرق لضو ابط اللغة العربية ولثو ابت الإسلام و عدم إخضاع ترجمته لمنهج العلمي يقتي اطلاعه على أهم المؤلفات الإسلامية في اللغةو علوم القرآن و الحديث. فقد أسس المستشرقون نظرياتهم عن الإسلام بالتشكيك في حقائقه وثو ابته، من أجل إعطاء صورة شنيعة عنه، فأولو ا اهتمامهم الثديد بالقر آن الكريم من خلال ترجمة معانيه وتأليف الكتب المتعلقة بعلومه.

انطلاقا من هذا المنظور الذي يرى في المستشرق ناقلا متحيز الأصوله ومتحاملا على كتاب المسلمين، القرآن الكريم و على الدين الإسلامي ومترجما مغرضا الى لغة ذويه من أهل الغرب، وكذلك انطلاقا من العداء الغربي الذي أحس به العرب و المسلمون في قر اءة المستشرقين لحضارتهم، لدينهم وللغتهم بتحقير هم مقارنة بالحضارة الغربية القائمة على الترفع وحب السيطرة، نثأ في صدور العرب و المسلمين بصفة عامة حقد وضغينة اتجاه الاستشر اق و المستشرقين استمر ا منذ بدايات الحركة الاستشر اقية، بتز امنها مع إر ادة الهيمنة الاستعمارية الأوروبية على الدول الإسلامية التي سقط فيها حكم الخلافة الإسلامية وتفتثت فيها المشاكل السياسية والاقتصادية والاجتماعية، الى يومنا هذا. وربما هنا يكمن سر إعراض المسلمين وتحريمهم للترجمة

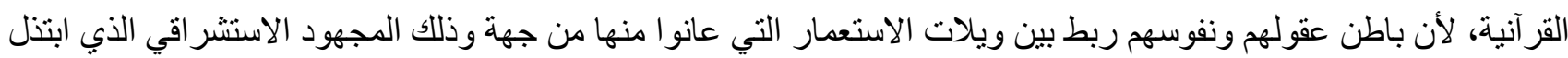
دينهم وثقافتهم وحضارتهم ولغتهم ومهد لاخول المستعمر لبلادهم. وللأف لا يمكننا إنكار أن كل هذه العو امل حاضرة الى يومنا هذا في الذاكرة الجماعية العربية والإسلامية ولها تأثير غير محمود على علاقاتتا مع الغرب. 


\section{المجلة الدولية لنشر البحوث}

International Journal of Research and Studies Publishing
المجلد الثاني - الإصدار التاسع عشر

تأريخ الإصدار: 20 مايو 2021م

ISSN: 2709-7064

العلاقة بين العرب و المسلمين و الغرب مسألة حضارية من الأهمية بمكان، اكتسبت مع مرور الوقت تأثير ا مهما نظر الما شهده وما يشهده العالم من تحو لات جذرية في كينونته. لهذا فإن البحث في كل ما يتعلق بحركة وعلم الاستشراق أضحى مهمة جسيمة بالنسبة لنا في ظل تقلص الفواصل بين الشعوب وتداخل المعارف والثقافات. ولكن يجب الأخذ بالاعتبار أن الرؤى

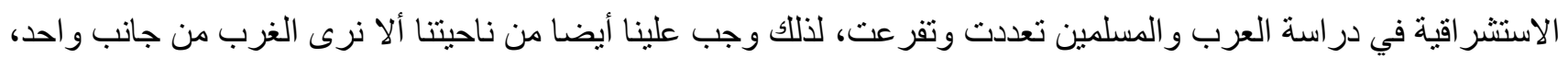
الجانب السلبي. ومن خلال هذه الدر اسة سوف نعيد رسالتنا التي تنفر من كل أنو اع العصبية و العنصرية بلفت الانتباه الى أنه كما كانت المقاصد مختلفة ومتباينة، فكذللك هي الأعمال. صحيح أن الجو انب السلبية للاستشر اق تتمثل في تعدد الأخطاء الثائنة في البحوث التي تتاولت سمات الدين الإسلامي البارزة والثقافة العربية بلغتها، المتعدة منها أو النابعة من الجهل بالآخر، و التي لا لا لهاء تخفى على كل ذي عقل راجح، لكن من جهة أخرى، فالنواحي الإيجابية تتجلى في العديد من الأمثلة، كقيام بعض المستشرقين


بفهرستها وتحقيق عدد كبير منها.

\section{ترجمة القرآن الكريم:} $-3$

\section{1-3 ترجمة ألفاظه أو ترجمة معانيه؟}

تطرقت العديد من الأبحاث في علم الترجمة لمشكلة الترجمة الحرفية المنساوية والفرق بينها وبين الترجمة التي تهتم أكثر بالنص في لغة المستقبل، بحيث يحاول فيها المنرجم إعطاء الأولوية لفهم معاني النص الأصلي أو النص المنبع ونقلها الى اللغة

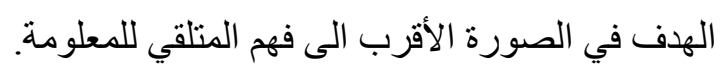

بالنسبة للترجمة الحرفية للقر آن، من المهم أن نعلم أن كتاب الله ثَعْيلّ نزل لهدفين رئيسين:

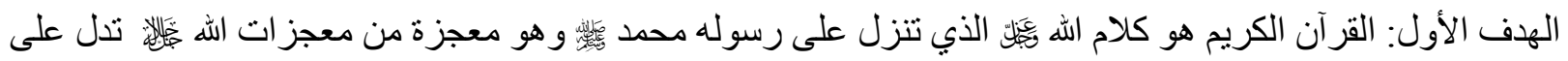
صدق النبي صلى الله عليه وسلم في الرسالة التي بلغته من رب العزة، أب كلام الله المعجِ للبشر الذب لا يستطيعون أن يأنوا بمثله ولو اجتمعوا مع الجن على ذلك. ويكمن إعجاز كتاب الله تعالى في خو اصه النحوية واللغوية و البلاغية التي لا يمكن نقلها إلى اللغات الأخرى مهما كانت لها خو اصها هي أيضا. لهذا السبب استحالت الترجمة الحرفية، لأنه لو تُرجم القر آن حرفيا ستضيع بكل تأكيد هذه الخو اص الفريدة المقصورة عليه، وستُنزع عنه صفة الإعجاز ودلالته على صدق نبينا

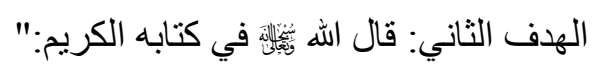

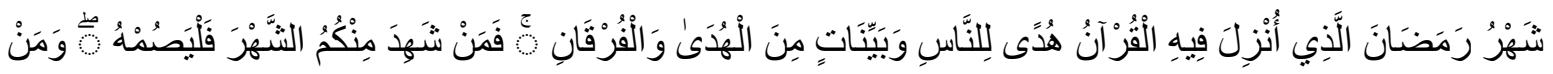

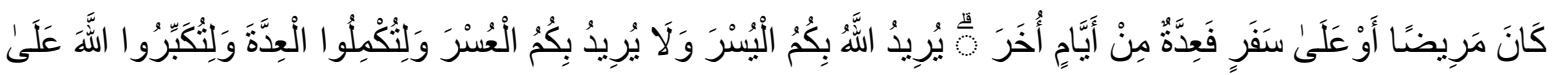

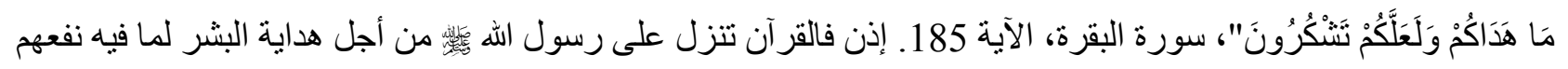

في الدنيا والآخرة من خلال استنباط الأحكام و العظات منه. لكن إذا كانت المعاني الأصلية للقر آن سهلة الترجمة و إمكانية استنباط الأحكام منها حتى في اللغات الأخرى، فإن هناك معان أخرى ثانوية في كتاب الله ثيَّيَّ توجب اجتهادات العلماء و الأئمة من أجل جهد استنباط الأحكام و المو اعظ، ويستحيل منطقيا في هذه الحالة أن تتمكن الترجمة الحرفية من إعطاء المعنى المبتغى. 


\section{المجلة الدولية لنشر البحوث}

International Journal of Research and Studies Publishing

ISSN: 2709-7064
المجلد الثاني - الإصدار التاسع عشر.

تأريخ الإصدار: 20 مايو 2021م

أما عن الترجمة التي تُعنى بمعاني القرآن الكريم: فهي عبارة عن نقل لمعاني الآيات بلغة المُستقبِل دون الاكتر اث بالنظم العربي وترتيب الكلمات العربية، بحيث توجب على المترجم أن يفهم المعنى القرآني جيدا ثم يحاول نقله الى لغة المتلقي وفق قو اعدهاوتركيبها. من خلال هذا التقديم لقسمي الترجمة الأساسين ومدى قابلية النص القرآني للتو افق مع أحدهما، أضحى بإمكاننا الإقرار

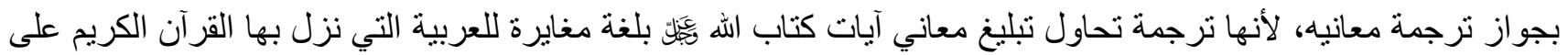
محمد ابن عبد الله

و علما أنه انعقد إجماع علماء المسلمين على جواز تفسير معاني القرآن الكريم بالعربية، فقد تكونت لدينا قناعة أن ترجمة معانيه جائزة بهذا الإجماع. لأنه إذا كان تفسير القرآن هو شرح نص الكلام الإلهي من أجل فهمه، تدبره، بيان معانيه، شرح الغامض فيه، و استتباط هدى الله يَّالِّا منه، فالترجمة التي تعنى بالمعنى تدخل في نفس هذا النطاق بما أنها ترجمة للمعنى لا للنص

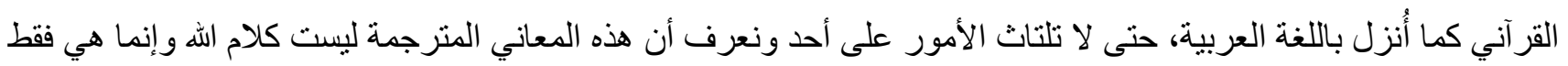
كلام المترجم. وبالتالي فالصلاة لا تجوز بها وكل مسلم حديث الدخول للإسلام مجبر على تعلم بعض السور من القرآن باللغة العربية كي تصح بذلك صلاته.

ترجمة القرآن من أجل إدراك معانيه واتباع هدى الله:

إن الترجمة القر آنية وحدها هي القادرة على إظهار ثوابت الإسلام لغير المسلمين لطرح سبل الحوار معهم ونوضيح موقف ديننا الحنيف من كل ما يتعلق بالدنيا والآخرة بصر احة وإيجابية في التعامل. لأن وصول الإسلام كان مشو هاً إلى كثير من الناس وكان عاملا مهما في خلق التوترات مع أهل الديانات الأخرى على مر الزمن. لأنهم للأسف، وهنا أخص بالذكر أهل الغرب، لم يعرفوا الإسلام إلاعن طريق المستشرقين وتصور اتهم المغلوطة عن الإسلام، التي حجبت عن معظم أهل هذه الديانات رفعة

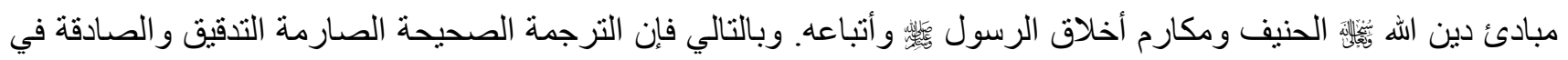
النو ايا لمعاني القرآن هي الكفيلة بفتح قلوبهم وبصائر هم أمام دعوة اله جل و علا، و هي التي بإمكانها إعانة الدعاة في و اجبهم الدعوي من أجل تبليغ رسالة الإسلام على أحسن وجه و إطلاع شعوب العالم على الهدي القرآني في لغاتهم التي شبوا عليها.

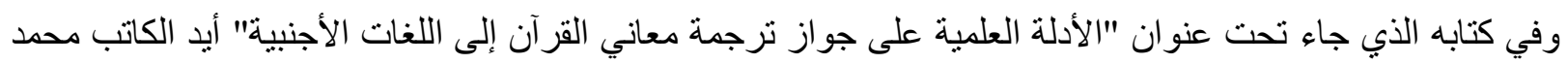

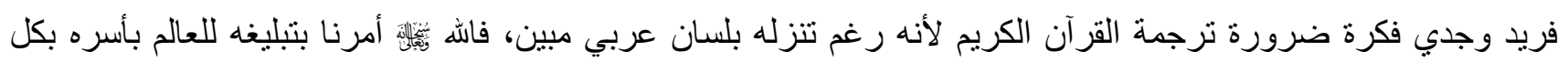
إمكانياتنا بما في ذللك من نقل لمعانيه إلى اللغات الأخرى. ولم يخطئ بناتا حين قال دفاعا عن مشروع ترجمة القرآن إلى اللغات الأجنبية وردا على معارضة الأستاذ محمد مصطفى الثاطر قائلا: 'لحن نعتقد ان القرآن كتاب لا تنقضي عجائبه ول بيرك غوره، كما بعتقد الاستاذ (الثاطر) ولكنا لا نذهب بالغلو في هذا المعنى إلى درجة التعطبل، واعتباره طلسما تضل العقول في فهمه، ولا تصل منه إلى حقبقة ثابتة فإن هذا الفهم بصطدم بالقر آن نفسه، فقد وصفه الهه في غير آية بأنه آيات بينات، وبأنه منزل لبتدبر الناس هذه الآيات، حتى قال: "ولقد ببسرنا القرآن للذكر فهل من مدكر"** ، اي سهلناه للاتعاظ وكررت هذه الآية أربع مرات في سورة واحدة..."، وقال أيضا: "و هنا ببوغ لنا أن نقول: إذا جربيا على مذهب الأستاذ الشاطر في تفسبر الآيات وترجنها، ثم

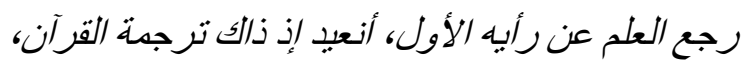




\section{المجلة الدولية لنشر البحوث}

International Journal of Research and Studies Publishing

ISSN: 2709-7064
المجلد الثاني - الإصدار التاسع عشر تأريخ الإصدار: 20 مايو 2021م

أم نترك الترجمة على خطائها ولكن الترجمة على الأسلوب الذي ذكرناه فلا تجعل محلا لمثل هذا الندم، لأن الكلمة قد تبدلت إلى ما بر ادفها في الإفادة، من دون التعرض للشرح و البيان، تاركين ذلك إلى فهم القراء، كما هو الحال بالنسبة إلى الكلمة

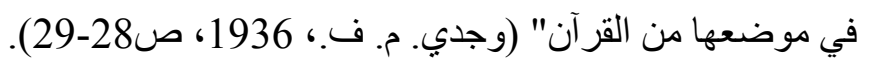

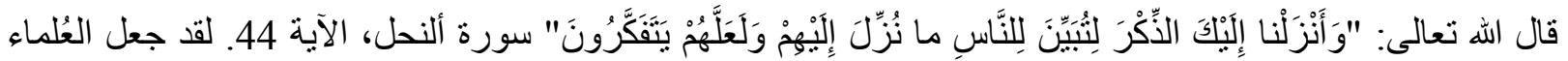
التفسير من فروض الكفاية، لأن وجود المفسرين في الأمة هو من واجبات الدين، و أنه علم وجب تعلمه. إذن فنحن نبني استنتاجنا على هذا الأساس: بما أن ترجمة معاني القرآن هي نقل لمعانيه فقط للقرآن بلغة أخرى وشرح لها، إذن فهي من الأمور الواجبة على المسلمين لما ينشأ عنها من منافع، كتعريف معاني القرآن و إيصال هدى الله جل جلاله لكل من لا يفهم اللغة العربية بتبليغ عقيدة ديننا الصحيحة وشر ائعه الكريمة التي تضمن للإنسان سبل العيش الكريم وتجيب على متطلبات حياته ماديا وروحيا، وأيضاً هي السبيل للدفاع عن كتاب الله ثيَّلْ بتبيان تدليس من تعمد الإخطاء في ترجمته ليُظهره لكل من جهل لغته في صورة سلبية تبعد من يريد اعتناق الإسلام عن سبيل الرشاد و الهدى.

\section{مشاكل ترجمة معاني القرآن وشروطها: (الأمير. أ.، بلون)}

أو لا يمكننا أن نصنف المشاكل التي تصادف المترجم في الترجمة القر آنية في ثناث أقسام:

1 ـ ـمشاكل خاصة: و هي مشاكل تخص المتلقي في لغته المغايرة للعربية و الخلفيات التي قد تؤثر على فهمه للنص المترجم.

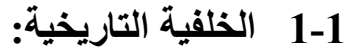

يجب أن يعرف المترجم أن المتلقي غير العربي لا يتوفر على خلفية تاريخية عن الأحداث التي وردت في كتاب الله التي تخول له وضع النص في سياقه التاريخي من أجل فهمه وربما قد تتكون لديه أحكام مغلوطة عن هذه الأحداث إذا لم ينتبه المترجم إلى ذللك، لهذا فيجب عليه تناول الآيات بطريقة توضح ظروفه سئ التاريخية.

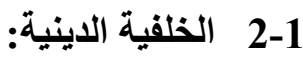

كل مترجم للقرآن ملزم بأن يعلم أن المتلقي الأجنبي عن لغة القرآن هو أيضا أجنبي عن أحكامه و إرشاداته. إذن من أجل

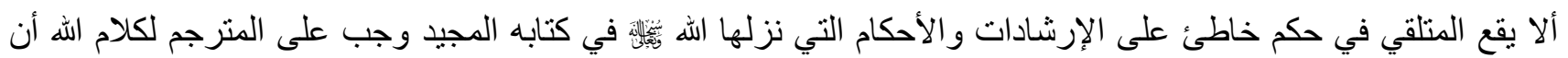
يوضح كل غموض قد يلفها إيضاحا جليا في ترجمته حتى و إن اضطر الى الإسهاب في نرجمنه.

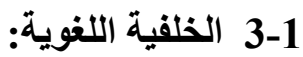

اللفظ العربي القر آني جامع لعدة معاني، أما القارئ الأجنبي عن لغتنا فهو لا يتوفر على أب خلفية لغوية عربية، لهذا فإنه موجب على المنرجم أن ينقل المعنى الذي يصوره اللفظ القرآني في إدر الك المتلقي العربي إلى إدر اك المتلقي غير العربي بألفاظ مناسبة في لغته، تحافظ على المعنى السليم، وتجنب التعامل مع المتلقي في اللغة الهدف على أنه مدرك لألفاظ القر آن ومفاهيمها. 


\section{المجلة الدولية لنشر البحوث}

International Journal of Research and Studies Publishing
المجلد الثاني - الإصدار التاسع عشر

تأريخ الإصدار: 20 مايو 2021م

\section{4-1 الخلفية الثقافية:}

لكل ثقافة آدابها ودلالاتها، ولها مصطلحاتها التي قد لا تُفهم بل وتصبح كلمات مبهمة إذا ثُرجمت إلى لغة أخرى دون مر اعاة الاختلاف الحضاري و النقافي. لهذا فيجب على المترجم القر آني أن يحترم هذه الفروق حتى يعطي نصا سلسا سهل الفهم بالنسبة للمنلقي.

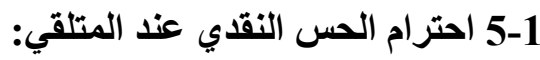

بما أن اللفظ العربي القرآني جامع لعدة معاني فإن الترجمة موجبة بأن تر اعي الحس النقدي لدى المتلقي باختيار الترجمة

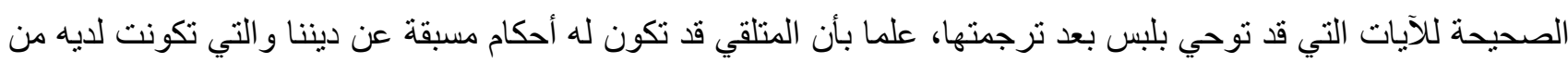
خلال نر اجم ومؤلفات أخرى مُغْلِطَة.

2 ـ مشاكل عامة: تتعلق بالصفات و الميز ات التي يجب أن تتوفر في المترجم القر آني حتى يكون مجهوده موفقا.

\section{1-2}

الترجمة القر آنية هي عمل من الأهمية بمكان و لا تحتمل الارتجال والابتداه، لذلك فمن المستحب أن يكون المترجم ممن عمل في مجال الدعوة لغير المسلمين حتى يتمكن من فهم عقلية المتلقي ويستطيع الوصول إليها بأدق العبار ات وأصح الألفاظ. ومن جهة أخرى يجب أن يكون المترجم متخصصا في مجالات الفقه الإسلامي و علوم القرآن وعلوم التفسير مطلعا على أهم المؤلفات التي نشرت في هذه التخصصات حتى تخلو ترجمته من الأخطاء الناتجة عن جهل بهذه العلوم.

\section{2-2}

إن لم يكن المترجم متقنا لفن الكتابة والصياغة فسوف يصل الكتاب للقارئ بصورة مشوهة المعنى والدلالة. من جهة أخرى فعلى المنرجم، ناهيك عن إتقانه للغة القر آن الكريم، أن يكون مطلعا على حضارة وثقافة اللغة الهدف حتى تكون ترجمته و اضحة سلسة الأسلوب بالنسبة للقارىئ الأجنبي لأن اختلاف الثقافات يغير معنى الكلمات عند نقلها من لغة لأخرى.

\section{3-2}

من البديهي أن المترجم بالإضافة لإلمامه بالعلوم الدينية وبحضارة المنلقي وثنقافته ولغته يجب أن يكون على در اية تامة بخبايا فن الترجمة وتقنياته وطريقة نقل المعاني القر آنية من لغة الضاد إلى اللغة المستقبلة للمعلومة.

\section{4-2 مثكلة التأهيل في تخصص الترجمة الاينية والقرآنية:}

مما يُؤسف له أن تغيب في مدارس الترجمة وكليات الدر اسات الإسلامية شعبة خاصة بالترجمة الدينية و القر آنية، حيث أن

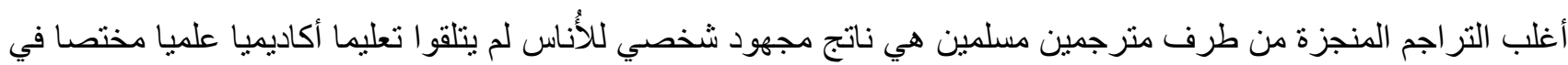
هذا العلم القائم بذاته والبالغ الأهمية. لهذا، و الأمر جلل، استوجب من القائمين على ميدان الترجمة في بلاد العرب والإسلام أن يخلقوا هذا الاختصاص في جامعاتنا ومدارسنا العليا، 


\section{المجلة الدولية لنشر البحوث}

International Journal of Research and Studies Publishing

ISSN: 2709-7064
المجلد الثاني - الإصدار التاسع عشر

تأريخ الإصدار: 20 مايو 2021م

الذي سيخول لمنرجمينا أن يكتسبوا الخبرة الفنية اللازمة في هذا العلم وطرق ترجمة النص الديني بصفة عامة وترجمة معاني القر آن بشكل خاص.3- المشاكل العملية: وهي المشاكل التي تتعلق بالجانب التنفيذي لجهد الترجمة:

1-3 الابتعاد عن متطلبات الترجمة و عدم احتر ام معايير ها.

2-3 ابتعاد النص المترجم عن النص الأصلي.

3-3عدم احتر ام الثروط التي يجب أن تتو اجد في النص المنقول إلى اللغة المستقبلة.

4 - 1 - 1

1-4

- إذا كانت رسالة القر آن الكريم كونية تنزلت على رسولنا محمد ابن عبد الله

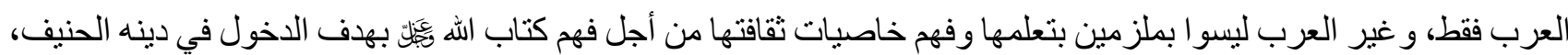
لأن التعريف بالإسلام و عقيدته و أحكامه وقر آنه دور منوط بأهل العربية ومن أحسن فهمها و التكلم بها من المسلمين.

- بما أن الترجمات المغلوطة والمُغْلِطَة في يومنا هذا منتشرة بكثرة وفي كل مكان، ترجمات اعتر اها القصور و اتسمت بإغر اض أصحابها، و اتصفت بتعدد عيوبها، وهي بتو اجدها وتعددها تزيد من الإساءة لدين الله تعالى وللمسلمين، وجب على كل

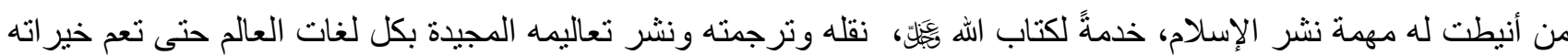

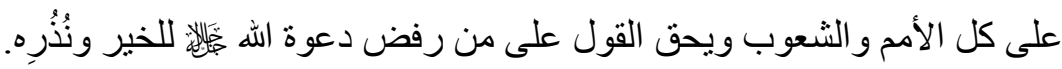

- إن كانت مهمة نشر الدين أمانة عظيمة في أعناق العلماء و الأئمة فهي كذلك أمانة جليلة بالنسبة للمترجمين لأنها من المتطلبات الجو هرية للاعوة إلى الله

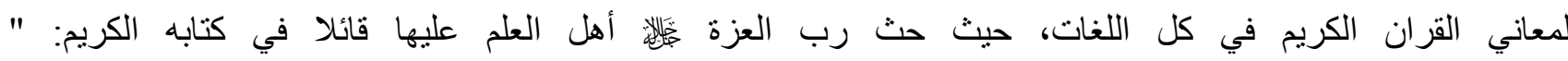

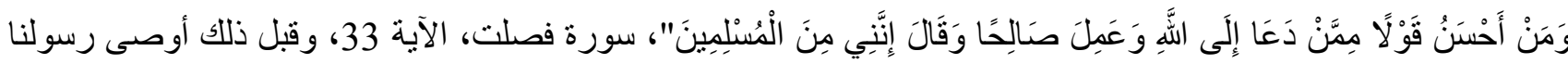

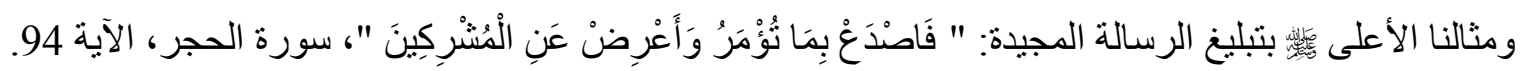

ـ العمل على نرجمة القر آن يوجب على كل من يمتهن الترجمة الخضوع لنظرة موحدة شاملة في مجهودهم حتى لا تختلط الأمور على الناس وتثيع الفوضى في التراجم المعروضة وكذا في فهم المعاني المترجمة بالنسبة للمتلقيين الأجانب عن لغة العرب. وبذلك يجب ألا تختلف الترجمات عن النص القر آني الأصلي إلا في أمور بسيطة لا تبدل الصورة التي جاء بها الأصل. ـ لقد أجريت محاو لات كثيرة لترجمة معاني القر آن الكريم لمختلف اللغات التي يتكلم بها المسلمون و غير هم، و أظهرت هذه الأعمال صعوبة مهمة المترجم في إيجاد كلمات دقيقة وفية لمعاني مفردات القرآن العربية باللغات المنرجم إليها. فلاحظنا تباين تللك الترجمات في جودتها وحصافتها اللغوية، وهذا نظر الكونها محاو لات فردية استدعت من أصحابها سنوات طويلة من الجهد الثاق و المضني. هذا في غياب نظرة موحدة لجميع الدول الإسلامية تستغل التقدم العلمي والتكنولوجي في ميدان المعلوميات و الترجميات من خلال خلق قو اعد للبيانات مناحة للمترجمين في كل أنحاء العالم، عبر الأنترنت، 
الهجلة الدولية لنشر البحوث

International Journal of Research and Studies Publishing

ISSN: 2709-7064
المجلد الثاني - الإصدار التاسع عشر. تأريخ الإصدار: 20 مايو 2021م

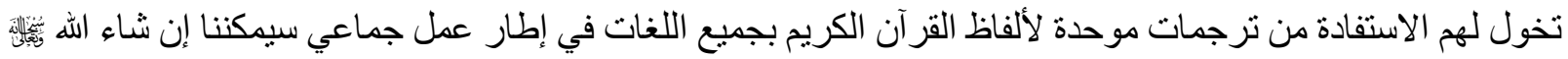
من إنتاج ونشر ترجمات لمعاني القرآن بدون اختلافات مريبة تشكك المتلقي الأجنبي في صدق عقيدتنا ومكارم الأخلاق التي بدعونا إليها ديننا الحنيف. 5- قائمة المصادر والمراجع: - القرآن الكريم - التفاسير: ـ الطبري، محمد بن جرير ، و آخرون. الباحث القرآني. تم الاسترجاع من الر ابط Www.tafsir.app

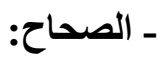
ـ البخاري، محمد بن إسماعيل، و آخرون، الدرر السنية. تم الاسترجاع من الر ابط

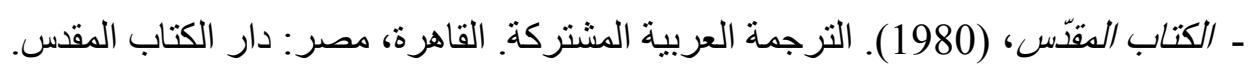
ـ - المعاجم:

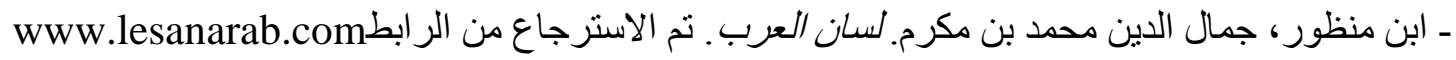

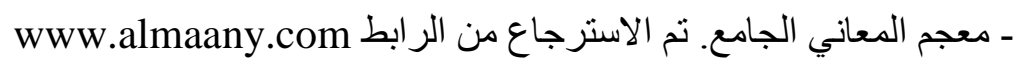
ـ الكتب: ـ ابن تيمية، تقي الدين، أبو العباس أحمد بن عبد الحليم الحراني. (1995). مجموع القتاوى. تحقيق بن قاسم، عبد الرحمن بن محمد. المدينة المنورة، العربية السعودية: مجمع الملك فهد لطباعة المصحف الثريف. ـ التمسماني، محمد حمادي الفقير. (2001). تاريخ حركة ترجمة معاني القرآن الكريم من قبل المستشرقبن ودوافعها وخطر ها. المدينة المنورة، العربية السعودية: مجمع الملك فهذ لطباعة المصحف الثريف. ـ ديدات، أحمد. (بدون تاريخ). الحل الإسلامي للمشكلة العنصرية، نرجمة وتعليق مختار، محمد. القاهرة، مصر : المختار الإسلامي، ـ الأمير، أحمد. (بدون تاريخ). ضوابط ومعايير في ترجمات معاني القرآن الكريج. أثنينا، اليونان: المركز الأوروبي للار اسات الإسلامية.

- ريكور، بول. (2008). عن الترجمة، ترجمة خمري، حسين. بيروت، لبنان: الدار العربية للعلوم ناشرون. ـ زقزوق محمود حمدي. (1970). الاستشراق والخلفية الفكرية للصراع الحضاري. القاهرة، مصر: دار المنار ـ الزيادي، محمد فتح الله. (1984). ظاهرة انتشار الإسلام وموقف المستشرقين منه. طر ابلس، ليبيا: المنشأة العامة للنشر و التوزيع والإعلان.

ـ سرى، طارق. (2006). المستشرقون ومنهج التزوير والتلفيق في التراث الإسلامي. القليوبية، مصر : مكتبة النافذة. ـ سعيد إدوارد. (2006). الاستثراق ـ الدفاهيم الغربية عن الثرق. القاهرة، مصر : دار رؤية. ـ العزب، محمود. (2006). إشكاليات ترجمة معاني القرآن الكريم، القاهرة، مصر، نهضة مصر. 
الهجلة الدولية لنشر البحوث

International Journal of Research and Studies Publishing

ISSN: 2709-7064
المجلد الثاني - الإصدار التاسع عشر تأريخ الإصدار: 20 مايو 2021م

ـ قارة، عبد العزيز عبد الرحمن. (1995). الإسلام والعنصرية وتفاضل القبائل وذوي الألوان. جدة، العربية السعودية: دار

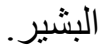

ـ قرقوتي، حنان. (2006). اللغة العربية والخط وأماكن العلم والمكتبات الترجمة وأثار ها . بيروت، لبنان: مجد المؤسسة الجامعية للار اسات و النشر و التوزيع.

ـ الندوي، عبد اله عباس. (1996).ترجمات معاني القرآن الكريم وتطور فههه عند الغرب. دعوة الحق 174 ، مكة المكرمة: دعوة الحق، رابطة العالم الإسلامي. - وجدي محمد فريد. (1936). الأدلة العلمبة على جواز ترجمة معاني القرآن الى اللغات الأجنبية. مجلة الأزهر، مصر : مطبعة المعاهد الدينية.

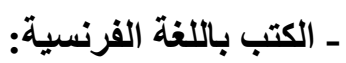

Calvet Louis-Jean. (2005). La guerre des langues - Et les politiques linguistiques. Paris, France : Hachette Littératures.

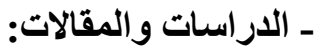
ـ النجار، شكري. (1983). لم الا هتمام بالاستشراق. الفكر العربي 31. طر ابلس، ليبيا.

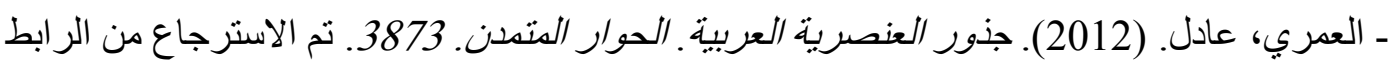
www.ahewar.org/debat/s.asp?aid=327281

ـ عالم، شوق شاكر. (2006). الاستشر/ق: أخطر تحد للإِلام. دراسات، 3/ ص. 63-78 ، شيتاغونغ: الجامعة الإسلامية العالمية. نم الاسترجاع من الر ابط

Doi: doi.org/10.52133/ijrsp.v2.19.5 